\title{
Milk for Skeletal Muscle Health and Sarcopenia in Older Adults: A Narrative Review
}

This article was published in the following Dove Press journal:

Clinical Interventions in Aging

\author{
Antoneta Granic (D) ${ }^{1,2}$ \\ Christopher Hurst (D) ${ }^{1,2, *}$ \\ Lorelle Dismore ${ }^{3, *}$ \\ Terry Aspray iD 1,2,4 \\ Emma Stevenson ${ }^{5,6}$ \\ Miles D Witham (iD) ${ }^{1,2}$ \\ Avan A Sayer ${ }^{1,2}$ \\ Sian Robinson ${ }^{1,2}$ \\ 'AGE Research Group, Translational and \\ Clinical Research Institute, Faculty of \\ Medical Sciences, Newcastle University, \\ Newcastle Upon Tyne, UK; ${ }^{2} \mathrm{NIHR}$ \\ Newcastle Biomedical Research Centre, \\ Newcastle Upon Tyne Hospitals NHS \\ Foundation Trust and Newcastle University, \\ Newcastle Upon Tyne, UK; ${ }^{3}$ Northumbria \\ Healthcare NHS Foundation Trust, \\ Research and Development, North Tyneside \\ General Hospital, North Shields, UK; \\ ${ }^{4}$ Newcastle Upon Tyne Hospitals NHS \\ Foundation Trust, Musculoskeletal Unit, \\ Freeman Hospital, Newcastle Upon Tyne, \\ UK; ${ }^{5}$ Population Health Sciences Institute, \\ Faculty of Medical Sciences, Newcastle \\ University, Newcastle Upon Tyne, UK; \\ ${ }^{6}$ Human Nutrition Research Centre, \\ Newcastle University, Newcastle Upon \\ Tyne, UK
}

*These authors contributed equally to this work

Correspondence: Sian Robinson NIHR Newcastle Biomedical Research Centre, Newcastle Upon Tyne Hospitals NHS Foundation Trust and Newcastle University, Biomedical Research Building, 3rd Floor, Campus for Ageing and Vitality, Newcastle Upon Tyne NE4 5PL, UK Tel +44 (0) 191208I325

Email sian.robinson@newcastle.ac.uk

\begin{abstract}
Skeletal muscle aging manifests as a decline in muscle quantity and quality that accelerates with aging, increasing the risk of sarcopenia. Sarcopenia is characterized by a loss of muscle strength and mass, and contributes to adverse health outcomes in older adults. Intervention studies have shown that sarcopenia may be treated by higher protein intake in combination with resistance exercise (RE). In comparison, less is known about the role of whole protein-containing foods in preventing or treating sarcopenia. Liquid milk contains multiple nutrients and bioactive components that may be beneficial for muscle, including proteins for muscle anabolism that, alone or with RE, may have myoprotective properties. However, there is a lack of evidence about the role of milk and its effects on muscle aging. This narrative review considers evidence from three observational and eight intervention studies that used milk or fortified milk, with or without exercise, as an intervention to promote muscle health and function in older adults (aged 50-99 years). The observational studies showed no association between higher habitual milk consumption and muscle-related outcomes. The results of intervention studies using fortified milk in relation to elements of sarcopenia were also negative, with further inconclusive results from the studies using a combination of (fortified) milk and exercise. Although milk contains nutrients that may be myoprotective, current evidence does not show beneficial effects of milk on muscle health in older adults. This could be due to high habitual protein intakes $(>1.0 \mathrm{~g} / \mathrm{kg} \mathrm{BW} / \mathrm{d})$ in study participants, differences in the type of milk (low-fat vs whole) and timing of milk consumption, length of interventions, as well as differences in the sarcopenia status of participants in trials. Adequately powered intervention studies of individuals likely to benefit are needed to test the effectiveness of a whole food approach, including milk, for healthy muscle aging.
\end{abstract}

Keywords: sarcopenia, muscle health, whole foods, milk, myoprotective properties, older adults

\section{Introduction}

The natural loss of skeletal muscle mass after the age of 30 accelerates in later life. ${ }^{1}$ There are even steeper losses in muscle strength and power, ${ }^{1,2}$ adversely affecting physical functioning in older adults and increasing the risk of sarcopenia. Sarcopenia-loss of skeletal muscle strength and mass ${ }^{1,3}$ - is associated with adverse health outcomes in older adults, including frailty, falls, disability, hospitalization, and earlier death. ${ }^{3-8}$ Sarcopenia has a complex pathogenesis and no pharmacological treatments have yet been shown to be effective. Several cellular processes including low-grade inflammation, oxidative stress, anabolic resistance, motor unit denervation and mitochondrial dysfunction are thought to contribute to reduced myofibre quantity and quality with aging. ${ }^{9,10}$ Current recommendations for 
treatment and prevention of sarcopenia focus on modifiable lifestyle factors such as diet and nutrition in combination with physical exercise ${ }^{9,11}$ mostly using a single nutrient approach. ${ }^{11-16}$ Using a whole food or whole diet approach, accounting for the combined effect of multiple food components on muscle has emerged as a treatment paradigm only recently. ${ }^{17}$ For example, a protein intake higher than the recommended daily allowance of $0.8 \mathrm{~g} / \mathrm{kg}$ body weight/day ( $\mathrm{g} / \mathrm{kg} \mathrm{BW} / \mathrm{d}$ ) has been debated as optimal for maintaining and regaining muscle mass and better physical performance in healthy older adults ${ }^{11-15}$ - preferably by consuming high-quality, protein-rich foods distributed across meals. ${ }^{16}$ Dietary protein sources and isolated protein supplements such as whey that have a higher content of branched-chain amino acids (BCAA) (eg, $13.4 \%$ leucine in whey) - an established regulator of muscle protein anabolism ${ }^{18}$ - have been regarded as superior for muscle mass and performance in younger and older adults. $^{19,20}$ However, less is known about how whole protein-containing foods, that are also rich in other essential nutrients and bioactive components, may be myoprotective and influence muscle health and function in older adults. $^{21}$ Protein-containing foods that are affordable and easy to prepare also need to be acceptable to older adults and a sustainable dietary source for the environment. ${ }^{22,23}$ Bovine milk is an attractive candidate whole food for evaluation because of its nutrient composition and potential benefits for human health.

The purpose of this narrative review is threefold: (1) to discuss the potential myoprotective properties of liquid milk; (2) to summarize and discuss findings from observational and intervention studies of the effects of milk, with or without exercise, in relation to muscle-health outcomes and sarcopenia in older adults, and (3) to discuss the evidence needed to inform future interventions with whole foods, including dairy foods, for healthy muscle aging.

\section{Potential Myoprotective and Health Benefits of Liquid Milk}

\section{Nutritional Composition of Milk}

Milk and milk products (eg, yogurts and cheeses) are examples of whole foods dense in nutrients that may have potential for improving muscle mass ${ }^{21}$ and performance, ${ }^{24}$ and therefore increasing consumption could be a preventive strategy for sarcopenia. ${ }^{25}$ Liquid milk, an important part of a healthy diet for over six billion people, ${ }^{26}$ contains a range of nutrients ${ }^{27}$ and bioactive components ${ }^{28}$ that are potentially valuable for human health. ${ }^{26}$ On average, whole (bovine) milk provides high-quality proteins $(20 \%$ of whey and $80 \%$ of caseins), minerals (eg, calcium, phosphorus, magnesium, iodine), vitamins (eg, fat-soluble A and E and water-soluble B vitamins), carbohydrates (lactose and oligosaccharides), and fats - a mixture of 70\% saturated (SFA), and $30 \%$ of mono- (MUFA) and polyunsaturated fatty acids (PUFA). ${ }^{26}$

Specifically, in addition to its average protein content of $32 \mathrm{~g} / \mathrm{L}$, daily consumption of $500 \mathrm{~mL}$ of whole milk would make a significant contribution to other daily nutrient intakes; approximating $15-20 \%$ of the dietary recommended intake for vitamin A $(280 \mu \mathrm{g} / \mathrm{L}) ; 60-80 \%$ for riboflavin $(1.83 \mathrm{mg} / \mathrm{L})$; $90 \%$ for vitamin $\mathrm{B}_{12} ; 40-50 \%$ for calcium $(1.1 \mathrm{~g} / \mathrm{L}) ; 18-25 \%$ for zinc $(4 \mathrm{mg} / \mathrm{L}) ; 30 \%$ for selenium $(37 \mu \mathrm{g} / \mathrm{L}) ; 12-16 \%$ for magnesium $(100 \mathrm{mg} / \mathrm{L})$ and $50 \%$ of the requirements for iodine (for an average of $160 \mu \mathrm{g} / \mathrm{L}$ ) in US adults. ${ }^{26,29}$

Beyond protein, milk also provides bioactive peptides, which have several physiological effects, including antihypertensive, antithrombotic, antimicrobial and immunomodulatory effects. ${ }^{28,30}$ Briefly, $\alpha-(13 \mathrm{~g} / \mathrm{L})$ and $\beta$-caseins $(9.3 \mathrm{~g} / \mathrm{L})$ are precursors of several peptides, including those involved in the inhibition of angiotensin-converting enzyme (ACE), ${ }^{31}$ whilst $\beta$-lactoglobulin $(3.2 \mathrm{~g} / \mathrm{L})$ is recognized as a potential anti-oxidant and retinol carrier, and immunoglobulins (A, M, and $\mathrm{G} ; 0.7 \mathrm{~g} / \mathrm{L})$ and lactoferrin $(0.1 \mathrm{~g} / \mathrm{L})$ have been linked to immunoprotection (reviewed in Mills et al). ${ }^{28}$ In addition, milk contains essential fatty acids such as PUFA $(2.3 \%$ of total FA or $2 \mathrm{~g} / \mathrm{L})^{27,28}$ — although in low amounts — that can be manipulated by different farming practices (animal diet, management and season). ${ }^{32}$ Specifically, milk PUFA include linoleic acid (LA 18:2 $n-6 ; 18 \mathrm{~g} / \mathrm{kg}$ of total FA), $\alpha$-linoleic (ALA 18:3n-3; $6.9 \mathrm{~g} / \mathrm{kg}$ of total FA), and long-chain $n-3$ FA (LC $n-3 ; 1.8 \mathrm{~g} / \mathrm{kg}$ of total FA) that are metabolically active and have specific functions in cell membranes. ${ }^{27,32}$

In summary, milk is a complex food that contains a number of nutrients and other biologically active components that are beneficial for human health. Milk is also an established part of the diet for many older adults who are, in general, higher consumers compared with younger adults, ${ }^{33}$ and thus may provide them with nutrients and bioactive components relevant for aging muscle.

\section{Milk and Human Health}

Epidemiological studies have reported associations between higher milk/dairy intake, and better health and functioning across the life course. For example, higher 
milk/dairy intake has been associated with better bone mineralization in early life, and slower age-related bone loss and reduced risk of hip fractures in later life, ${ }^{34-37}$ favorable or neutral associations with different cardiovascular clinical outcomes (coronary artery disease, stroke, type 2 diabetes, hypertension, and metabolic syndrome) ${ }^{38}$ beneficial associations with body composition, ${ }^{39}$ and reduced risk of obesity ${ }^{40}$ and colorectal cancers in middleaged and older adults. ${ }^{41}$

Higher intake of milk was positively associated with performance in the 20-m endurance test and negatively associated with BMI in children aged 9-12 years, thought to be mediated through greater dietary intakes of milkderived vitamin $B_{2}$ and $B_{12}$, which contributed to higher cardio-respiratory fitness. ${ }^{42}$ In addition, intervention studies with fat-free and skimmed milk in combination with $\mathrm{RE}$ in young adults and athletes have shown higher lean muscle, fat mass loss, increased muscle strength, ${ }^{43,44}$ and greater muscle protein synthesis (MPS), ${ }^{45}$ compared with an isocaloric carbohydrate or soy-based drink. Ingestion of milk (including chocolate milk) post-exercise has been shown to attenuate exercise-induced muscle damage and soreness, increase MPS, and rehydrate muscles in athletes and young, active adults as effectively or even better that any other commercially available recovery drink. ${ }^{46,47}$ Taken together, studies in young adults highlight the potential health benefits of milk for muscle beyond anabolic effects of its main protein constituents (whey and caseins). However, little is known about how milk consumption may affect muscle health and function in older adults who are at high risk of sarcopenia and associated adverse health outcomes.

\section{Potential Mechanisms of Milk Effects on Skeletal Muscle Health in Older Adults}

A whole food approach in investigating the relationship between protein-rich foods and muscle with aging posits a number of myoprotective properties of unfortified milk, beyond those that are proanabolic (ie, MPS-promoting). These properties include anti-oxidative, anti-inflammatory, and immunomodulatory effects (Figure 1).

\section{Proanabolic Effect of Milk-Based Proteins: An Example of Whey}

Whey proteins in milk (such as $\beta$-lactoglobulin, $\alpha$-lactalbumin, lactoferrin, and immunoglobulins) are characterized as a fast-digestible proteins giving rise to a high concentration of essential amino acids (EAA) available to support MPS post-digestion. ${ }^{12,27,48}$ Whey is a rich source of the BCAA leucine $(13.4 \%$ or $122 \mathrm{mg} / \mathrm{g}$ of whey) ${ }^{30}$ which appears to be the most important EAA to stimulate MPS in skeletal muscle ${ }^{18,48}$ through the rapamycin (mTOR) pathway - a key regulator of human MPS in response to increased EAA. ${ }^{49}$ The ability of leucine to induce MPS has been explained by the "leucine threshold" hypothesis and demonstrated in numerous human and animal trials (discussed in Devries et al). ${ }^{48}$ The hypothesis posits that, in order to increase MPS after protein ingestion, the intracellular leucine concentration in myofibres has to reach a desired level, which can be altered by other stimuli, lowered by RE and increased by aging and sedentary lifestyle. ${ }^{48}$ For younger active men, the amount of leucine needed to exceed the threshold and induce maximal MPS has been estimated to be 1.7 to $2.4 \mathrm{~g}$ provided in $20 \mathrm{~g}$ of high-quality protein, or in a per meal feeding dose of $0.25 \mathrm{~g}$ protein $/ \mathrm{kg} \mathrm{BW} .^{50}$ For older adults, a higher protein (leucine) intake for MPS has been suggested because of anabolic resistance, and estimated to be 0.38 $\mathrm{g} / \mathrm{kg} \mathrm{BW}$ per meal. ${ }^{50}$ Numerous trials have shown a synergistic effect of protein supplementation and RE when protein ingestion follows a bout of $\mathrm{RE}$, resulting in a greater MPS compared with either stimulus alone (discussed in Devries et al). ${ }^{48}$ The whey (leucine) potential to augment the anabolic effect of prolonged exercise ( $>6$ weeks) has been show for fat-free mass and one repetition maximum (1-RM) leg press strength in a metaanalysis that included six trials with older adults (aged $>50$ years $)$, a mean difference of $0.91 \mathrm{~kg}(p<0.0001)$ and $20.7 \mathrm{~kg}(p<0.005)$, respectively. ${ }^{51}$

\section{Anti-oxidative, Anti-inflammatory, and Immunomodulatory Properties of Milk Bioactive Components}

Several lines of research have shown that oxidative stress and accumulation of reactive oxygen and nitrogen species (ROS/RNS) in aging muscle impairs cellular homeostasis and causes damage to key cell biomolecules (ie, proteins, nucleic acids, lipids) and organelles ${ }^{52}$ contributing to sarcopenia., ${ }^{9,10}$ A number of milk-derived bioactive peptides (eg, $\beta$-lactoglobulin, lactoferrin), ${ }^{26-28,30}$ lipids and fatty acids (eg, $\alpha$-linoleic acid, the milk fat globule membrane (MFGM) lipids and glycoproteins), ${ }^{26-28,53}$ and minerals (eg, selenium, zinc) have been shown to have anti-oxidative properties, which may add to the exogenous antioxidant capacity of a balanced diet in neutralizing ROS/RNS in myofibres. An anti-inflammatory effect is 


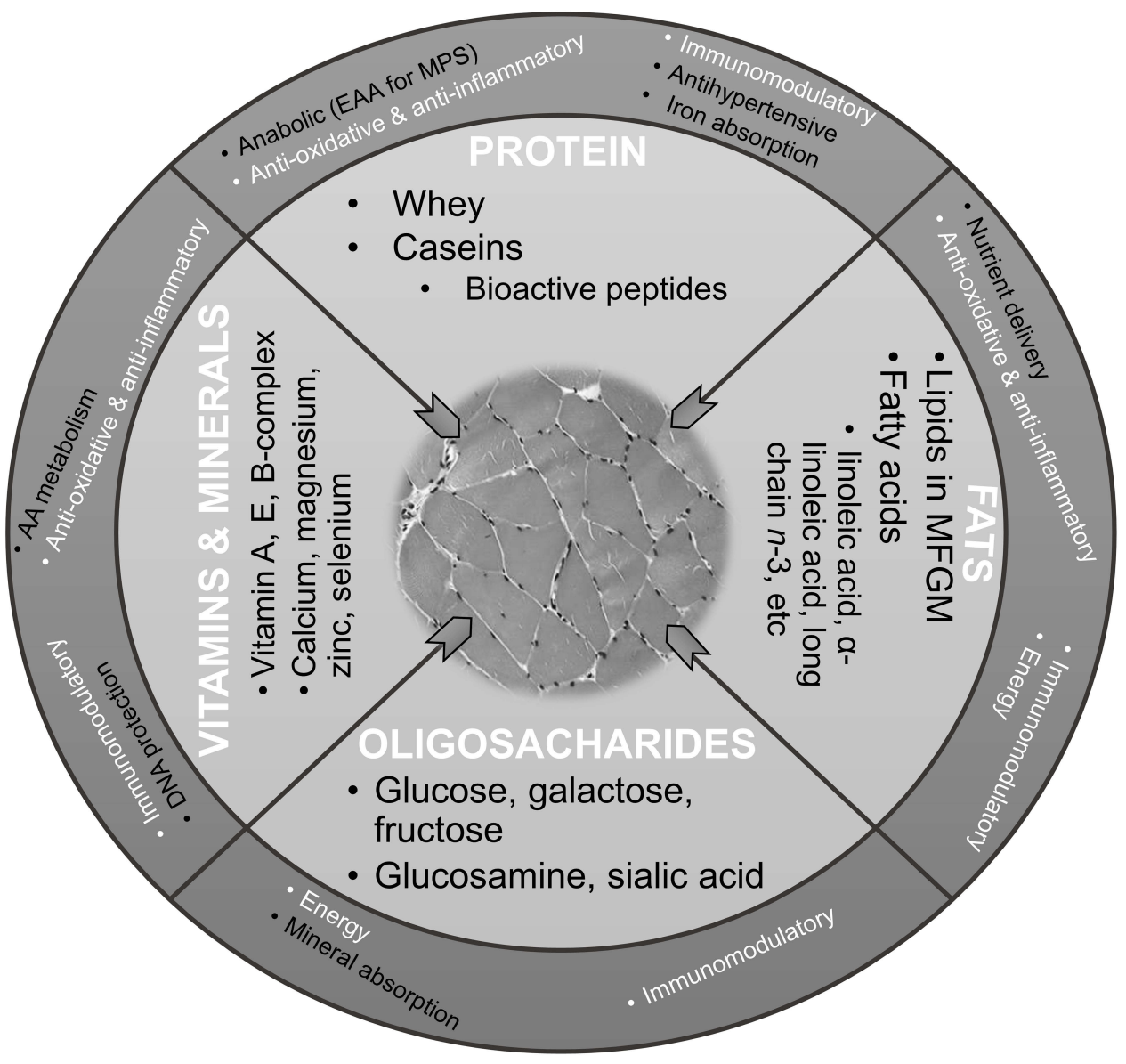

Figure I Hypothesized myoprotective properties of nutrients in liquid milk.

Notes: Hypothesized health effects and function of milk nutrients and bioactive components on muscle may include energy, minerals and vitamin delivery, anabolic, anti-oxidative, anti-inflammatory, and immunomodulatory pathways. Common pathways across the nutrients and non-nutrients are presented in the outer circle in white. (C) Newcastle University. This work is licensed under a Creative Commons Attribution-Noncommercial-Share Alike 3.0 Unported License https://creativecommons.org/licenses/by-nc-sa/3.0/. Abbreviations: EAA, essential amino acids; MFGM, milk fat globule membrane; MPS, muscle protein synthesis.

the other bioactivity associated with milk constituents (such as casein-derived bioactive peptides ${ }^{26,28}$ and $n-3$ PUFA) that may ameliorate inflammaging in muscle by reducing cytokine load (eg, by decreasing levels of interleukin 6 and 8 (IL- 6 and IL-8) and tumor necrosis factor $\alpha$ $(\mathrm{TNF}-\alpha)) .{ }^{52}$ Inflammaging, the age-related chronic lowgrade inflammation characterized by higher concentrations of pro-inflammatory mediators in serum and plasma, have been linked to worse age-related pathologies ${ }^{9,10,54}$ and loss of muscle mass and function. ${ }^{52,54}$ The n-3 PUFAs have been proposed as a therapeutic agent for sarcopenia because of their anti-inflammatory properties, anabolic effect on skeletal muscle metabolism through mTOR activation, and reduction of insulin resistance. ${ }^{55}$ Although investigations about the role of immune function in sarcopenia lag behind other mechanistic studies, a decline of innate immunity and its link with inflammaging has been postulated in the pathogenesis of frailty and sarcopenia. ${ }^{56}$
Milk contains several immunomodulatory components (eg, immunoglobulins, lactoferrin, $\alpha$-lactalbumin $)^{28}$ that may act against cytokine-derived inflammation.

Furthermore, antihypertensive bioactive peptides found in milk (eg, lactopeptides $\alpha$-lactorphin and $\beta$-lactorphin released from $\alpha$-lactalbumin and $\beta$-lactoglobulin, respectively) acting as ACE inhibitors ${ }^{28,31}$ may have potential as a therapy for sarcopenia. ACE inhibitors (including those that are milk-derived) may have multiple beneficial effects on aging muscle,${ }^{57}$ including the ability to reduce inflammation, promote glucose uptake, and improve endothelial function, angiogenesis and muscle blood flow. ${ }^{9,58}$ Synergistic and cumulative actions of milk-derived bioactive components through these pathways may enhance milk's proanabolic effects post-exercise. However, evidence is very limited and further research is needed to understand the bioactive potential of milk for healthy muscle aging. For example, future studies with older 
adults are needed to determine whether the presence of fats (fatty acids) in whole milk enhances absorption of EAA for MPS as observed in young athletes post-exercise, ${ }^{59}$ and in combination with other myoprotective effects, including the delivery of fat-soluble vitamins (eg, vitamin A, E, K) that may be relevant for muscle health.

In summary, myoprotective effects of milk may work through anabolic, anti-oxidative, anti-inflammatory and immunomodulatory pathways associated with the main nutrients in milk, including proteins, fats, vitamins and minerals, and milk sugars (Figure 1). Their synergistic and cumulative action may provide myoprotection beyond proanabolic effects of milk proteins such as whey.

\section{Evidence About the Role of Liquid Milk in Skeletal Muscle with Ageing Materials and Methods}

For the narrative summary of evidence, systematic searches of four electronic databases (MEDLINE, Embase, Web of Science, CENTRAL) were conducted independently by two researchers $(\mathrm{LD}, \mathrm{CH})$ for articles published in English in the period from January 2010 until June 2019. Observational and intervention studies were searched using the following search terms and their combination: "liquid milk", "fluid milk", "whole milk", "skimmed milk", 'milk-based drinks', "fortified milk", "grip strength", "physical performance", "muscle mass", "sarcopenia", "older adults", "elderly", "intervention", "randomized controlled trial" and "cohort study". Only full-text articles with clearly described populations (eg, community-dwelling older adults aged $\geq 65$ years), exposure and study arms (milk, fortified milk with or without exercise; excluding reconstituted milk-based drinks from powder or those insufficiently defined), study duration, outcome (muscle mass, strength, power, physical performance, sarcopenia), and power to support the conclusions were critically evaluated (CH, LD) and selected for the review. Relevant information from the selected articles were extracted independently ( $\mathrm{CH}, \mathrm{LD})$ and compared, including study name, duration, sex and age of participants, sample size, exposure, outcomes, main findings, and study limitations.

\section{Results}

\section{Evidence from Observational Studies}

Three observational studies (two articles) assessed evidence about the association between liquid milk consumption and muscle-related outcomes (Table 1). ${ }^{60,61}$ One study aimed to address the association between habitual consumption and physical performance in old age using data from the Boyd Orr study and the Caerphilly Prospective Study (CaPS). ${ }^{60}$ In the Boyd Orr study, a week-long dietary household inventory was completed by families, involving 4999 children (aged 0-19). Sixty-five years later, 405 men and women (mean age 70.7 years) took part in a detailed clinical examination involving physical performance tests. Individual consumption of whole milk (grams/day) was estimated from the household inventory. A higher childhood milk intake was associated with $5 \%$ faster walking times assessed by Timed Up-and-Go (TUG) test, and better balance in later life. However, the study found no association between adult milk intake and walking time, and a negative association between higher milk consumption and balance (Table 1). Contrasting results were observed in the CaPS study of 1195 men - a unit increase in whole milk intake (half a pint milk/day) at dietary assessment (age range: 59-73 years) was associated with $21 \%$ lower risk of poor balance at follow-up (age range: 66-86 years). The Boyd Orr findings suggest ensuring adequate milk consumption is a potentially modifiable health behavior in early years, to enhance physical performance in old age.

In the Helsinki Birth Cohort Study, a prospective study of over 1000 older adults (mean age 61 years at baseline) that assessed the association between a healthy Nordic Diet (ND) and physical performance at 10-year followup, low consumption of low-fat milk at baseline was independently associated with better overall Senior Fitness Test score in men but not in women. ${ }^{61}$ Low-fat milk (skimmed and milk with fat content $<2 \%$ ) consumption, a favorable component of ND score, was estimated from food frequency questionnaires and assigned a value of $0-3$ according to ascending sex-specific quartiles. The findings may have limited generalizability because those who were assessed at follow-up had healthier diets at baseline, were younger and more highly educated, and thus may not be representative of the general older adult population in Helsinki. In addition, uncontrolled confounding (eg, change in diet over time) and sex-specific differences in food choices (including milk) may have biased the results.

In summary, observational research investigating the association between liquid milk consumption, muscle strength and physical performance in older adults is scarce. We found only three studies focussed on older adults, and none of them have investigated the role of 


\begin{tabular}{|c|c|c|c|c|c|c|c|}
\hline $\begin{array}{l}\frac{n}{4} \\
\overline{\bar{y}} \\
\check{c}\end{array}$ & 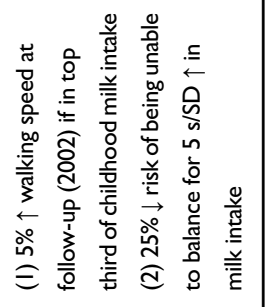 & & 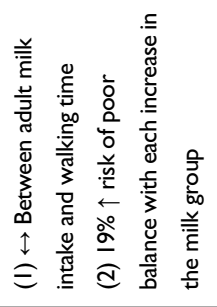 & & 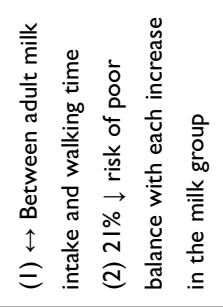 & & 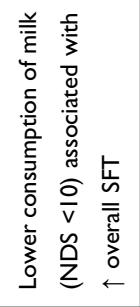 \\
\hline 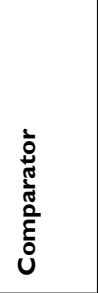 & 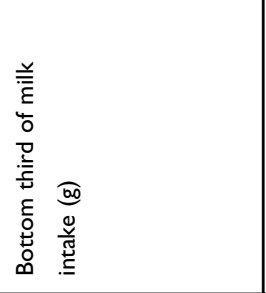 & & 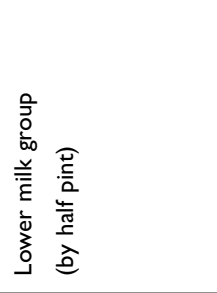 & & 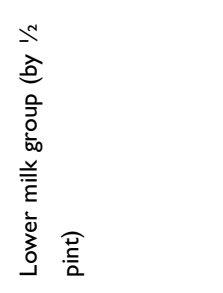 & & 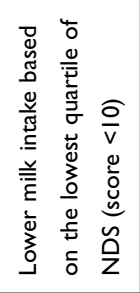 \\
\hline 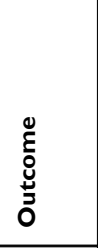 & & & 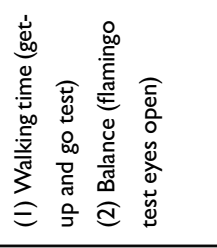 & & 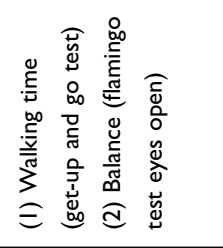 & & 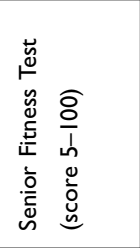 \\
\hline 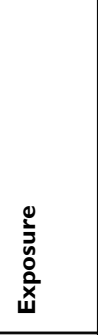 & 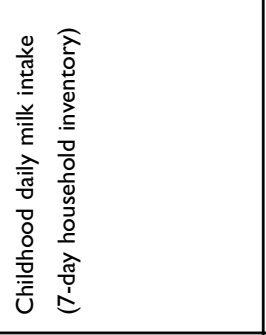 & 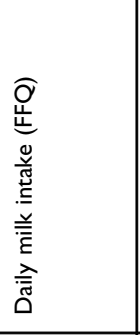 & 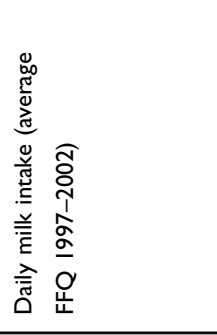 & & 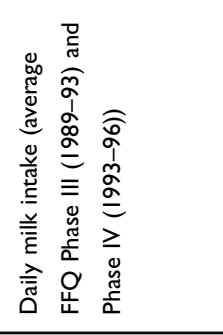 & 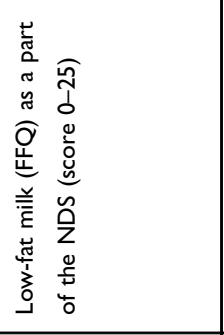 & \\
\hline $\begin{array}{l}\frac{5}{\frac{5}{d}} \\
\frac{d}{I} \\
\end{array}$ & 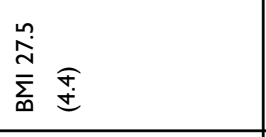 & & & & 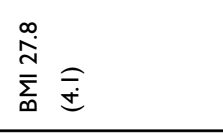 & 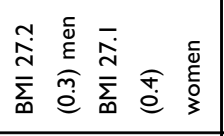 & \\
\hline$\frac{0}{\frac{0}{0}}$ & $\begin{array}{l}\text { oे } \\
\sigma\end{array}$ & 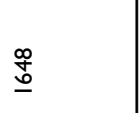 & $\stackrel{\text { on }}{\sigma}$ & $\stackrel{\sim}{\stackrel{\sim}{\sim}}$ & $\stackrel{\stackrel{\varrho}{\varrho}}{=}$ & 吉 & $\underline{\underline{0}}$ \\
\hline ڤั & $\sum_{\mathcal{L}^{*}}$ & $\sum_{\mathcal{L}^{*}}$ & $\sum_{\mathcal{H}}$ & $\Sigma$ & $\Sigma$ & $\frac{u}{\Sigma}$ & $\frac{u}{\Sigma}$ \\
\hline 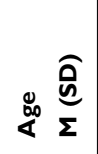 & 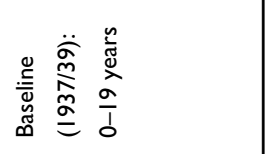 & 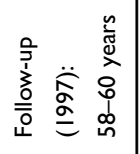 & 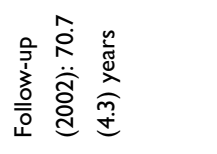 & 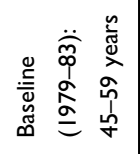 & 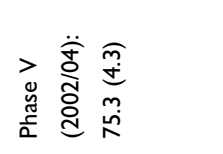 & 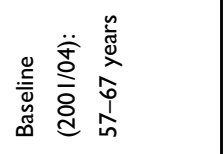 & 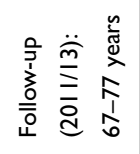 \\
\hline 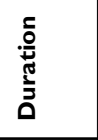 & 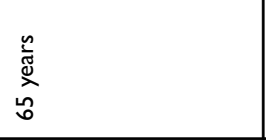 & & & 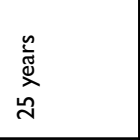 & & 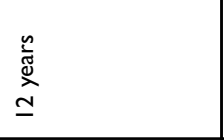 & \\
\hline 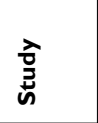 & 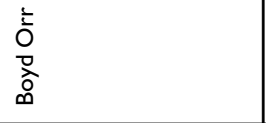 & & & $\begin{array}{l}\text { \% } \\
\text { ज̃ }\end{array}$ & & 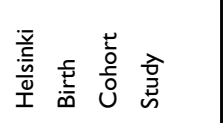 & \\
\hline نे & 弚 & & & & & 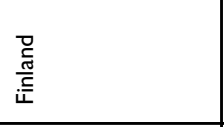 & \\
\hline 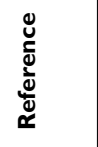 & 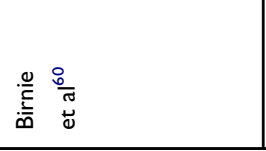 & & & & & 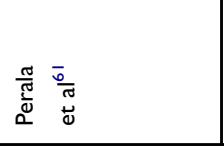 & \\
\hline
\end{tabular}


milk specifically in individuals with sarcopenia. Whilst higher childhood whole milk consumption might foster better physical performance and balance in later life, the results for the role of milk in muscle health and function in older adults were mixed, warranting further prospective research in older cohorts.

\section{Evidence from Liquid Milk and Fortified Milk Intervention Studies with and without Exercise}

\section{Main Characteristic of the Studies: Participants, Intervention and Outcomes}

In a recent meta-analysis of 14 randomized controlled trials (RCT) that investigated the efficacy of dairy protein supplementation on muscle strength, mass, and function in middle-aged and older adults (with or without sarcopenia), an increase in appendicular muscle mass (AMM) was observed with higher dairy protein intake, whilst the results for physical functioning were inconclusive. ${ }^{21}$ However, the evidence was based mainly on isolated dairy-source proteins with only two trials using whole foods (cheese).

To date, only a limited number of intervention studies have evaluated the effects of liquid milk or fortified milk (ie, with additional nutrients) on measures of muscle health and physical performance in older adults. These studies typically involve either: (1) milk supplementation alone or (2) a combination of milk supplementation and exercise training and are summarized in Table 2. Briefly, we identified eight intervention studies ${ }^{62-69}$ (two with milk supplementation alone ${ }^{62,63}$ ) and six with combined supplementation and exercise ${ }^{64-69}$ involving healthy (three studies $^{65,67,68}$ ) or (pre)sarcopenic community-dwelling older adults (two studies ${ }^{63,66}$ ), and older adults with physical impairments living in residential care facilities (three studies ${ }^{63,64,69}$ ). Seven were RCTs; ${ }^{63-69}$ three included only men. ${ }^{65-67}$ The studies enrolled older adults aged 50 to 99 years in samples ranging from 26 to 177 participants, with interventions lasting from 12 weeks to 18 months. Only one used fortified whole milk, ${ }^{62}$ and the remainder used reduced fat milk/low fat milk $(\leq 1.6 \% \text { fat })^{63-69}$ of which two used chocolate milk. ${ }^{66,67}$ Milk was fortified with several nutrients in all but one study, ${ }^{67}$ including protein, ${ }^{63,64,66,68,69}$ calcium and vitamin $\mathrm{D}^{62,65}$ and EAA. ${ }^{66}$ The amount of protein ingested via fortified milk varied from $10.5 \mathrm{~g}^{68}$ to $40 \mathrm{~g}^{63}$ consumed either every day or after exercise on the training days over the study period.
Muscle health and function-related outcomes also varied considerably across the studies, and included the measures of muscle mass (eg, total muscle mass, lean muscle mass, skeletal muscle index (SMI)), ${ }^{63-66,68}$ strength (eg, leg press, chest press, grip strength), ${ }^{62,63,65,67,68}$ and physical performance (eg, TUG, stair climb, chair rises, gait speed, balance). ${ }^{62,63,65,66,68,69}$

\section{Interventions Involving Fortified Milk: Evidence}

A study of 107 care residents (mean age $79.9 \pm 10.1$ years) found no association between fortified whole milk intake, TUG and grip strength following a six-month intervention designed to promote milk consumption. ${ }^{62}$ There was a trend for slower TUG time (mean (SD) -2.56 (15.6), $p=0.07)$ over the study period, but no difference in GS pre- and post-intervention $(17.4 \pm 0.9 \mathrm{~kg}$ vs $17.6 \pm 0.8 \mathrm{~kg}$, $p=0.7)$. However, the supply of milk to residents' diets (added to drinks and cereal) was left to the discretion of the nursing staff, aiming for a mean intake of $210 \mathrm{~mL} /$ day per resident. The median consumption was $160 \mathrm{~mL} /$ day and estimated based on self-reports. Consistent with this finding, a study of 50 community-dwelling older adults with reduced physical functioning, who were provided with $2 \times 400 \mathrm{~mL}$ of protein-enriched milk ( $2 \times 20 \mathrm{~g}$ protein) each day for 12 weeks, also showed no improvements in muscle mass, strength or functional performance when compared with a control group consuming an isocaloric, non-nitrogenous control drink. ${ }^{63}$ Specifically, although chest press improved significantly in the protein $(1.3 \mathrm{~kg}$ $(0.1-2.5), p=0.03)$ and control group (1.5 $\mathrm{kg}(0.0-3.0)$, $p=0.048$ ), no difference between the groups $(p=0.9)$ were observed. Furthermore, no significant change in leg press ( $p=0.9)$ or muscle mass $(p=0.54)$, or the physical performance tests (ie, chair rise, stair climb, and GS test; $p>0.05$ for all tests) were observed between the groups after the 12-week intervention. Importantly, in both studies baseline protein intake was $>0.8 \mathrm{~g} / \mathrm{kg} \mathrm{BW} / \mathrm{d}$, which would be expected to have affected the potential impact of (fortified) milk on muscle mass and function.

\section{Interventions Involving Fortified Milk and Exercise: Evidence}

In the longest duration intervention to date, an 18-month intervention, Kukuljan et $\mathrm{a}^{65}$ found no beneficial effect of fortified milk consumption $(2 \times 200 \mathrm{~mL}$ of reduced fat UHT milk consumed daily supplemented with $\mathrm{Ca}$ and vitamin $\mathrm{D}$ ), compared with resistance training alone on skeletal muscle size, strength or function in healthy older men with a higher 


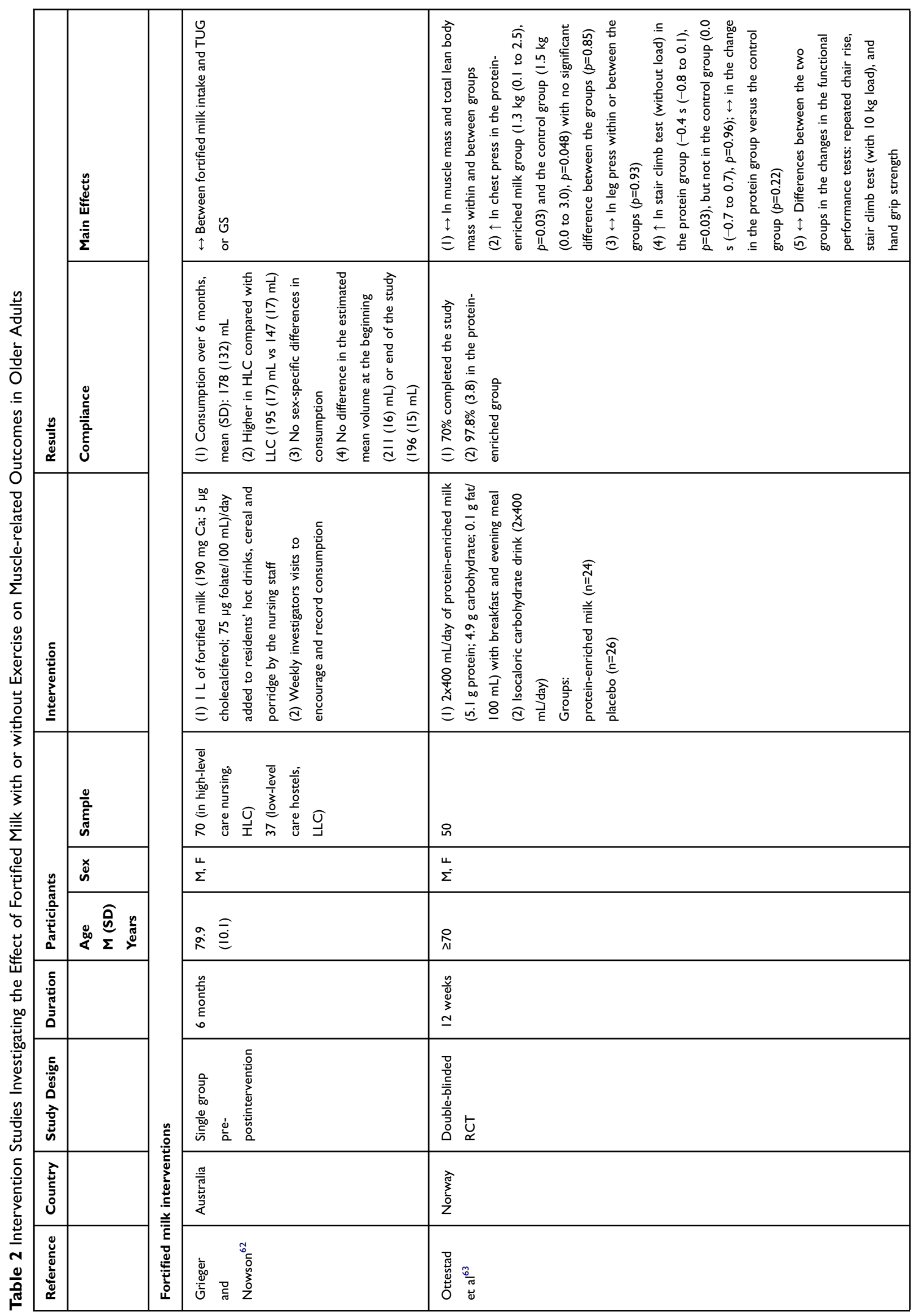




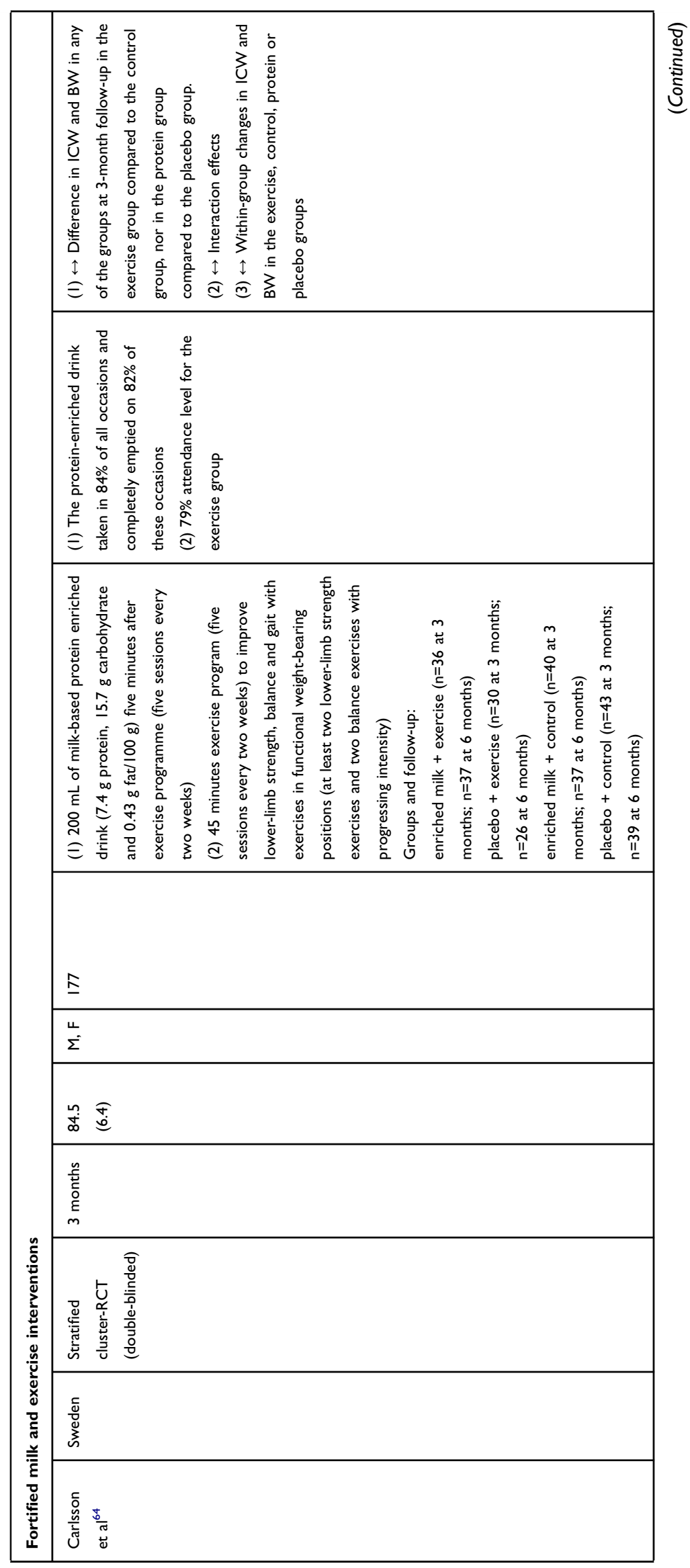




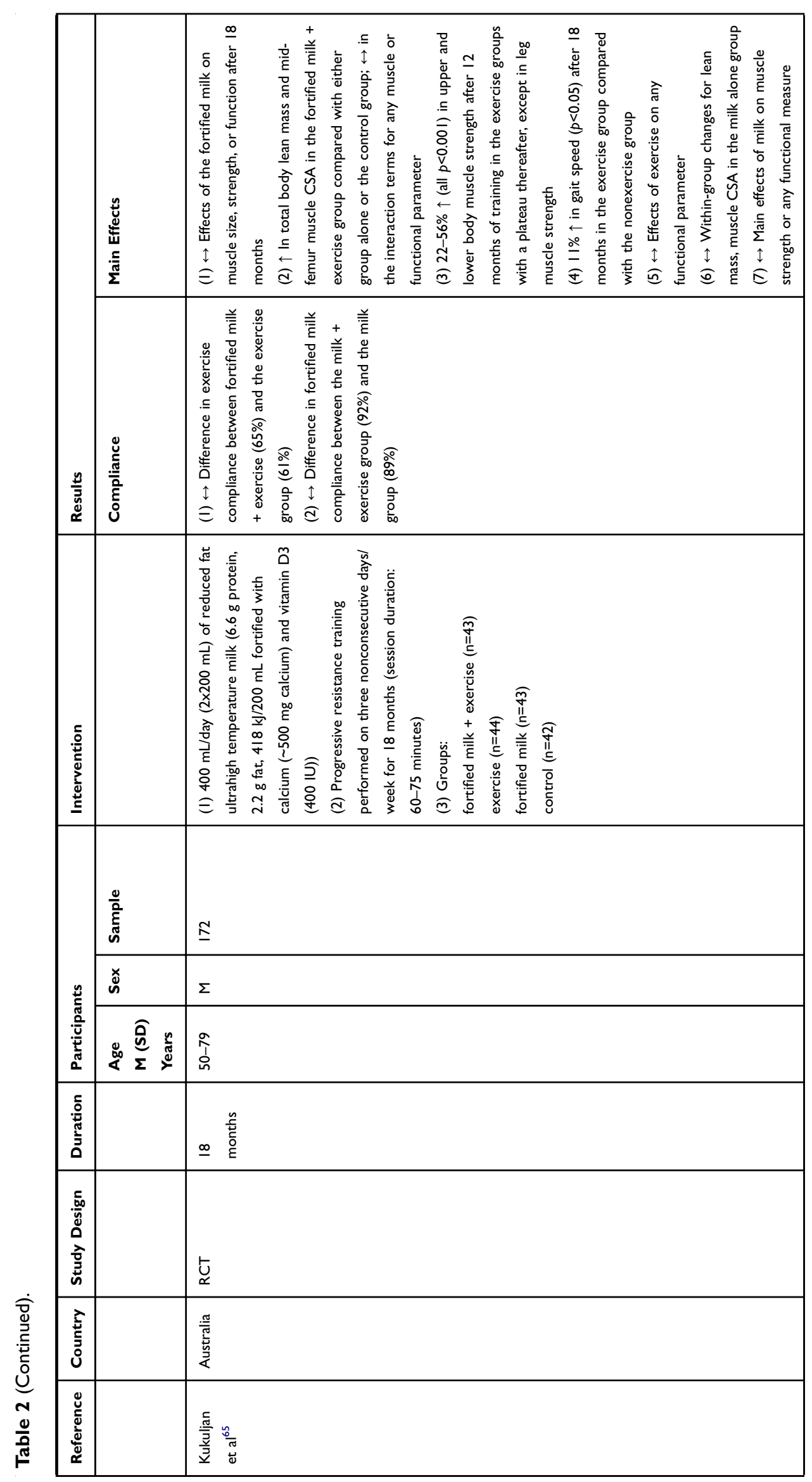




\begin{tabular}{|c|c|}
\hline 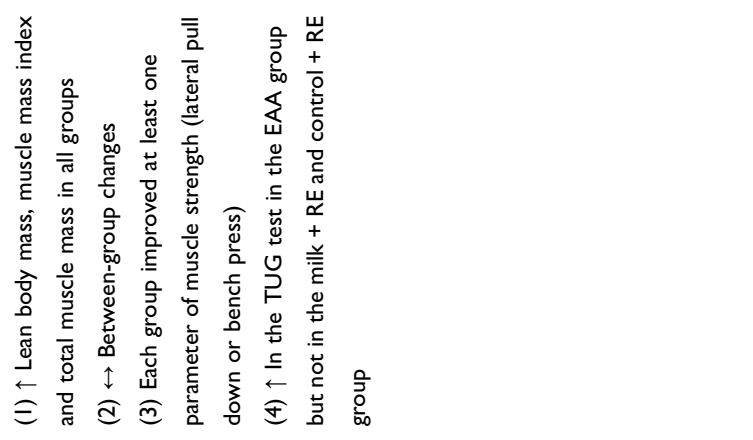 & 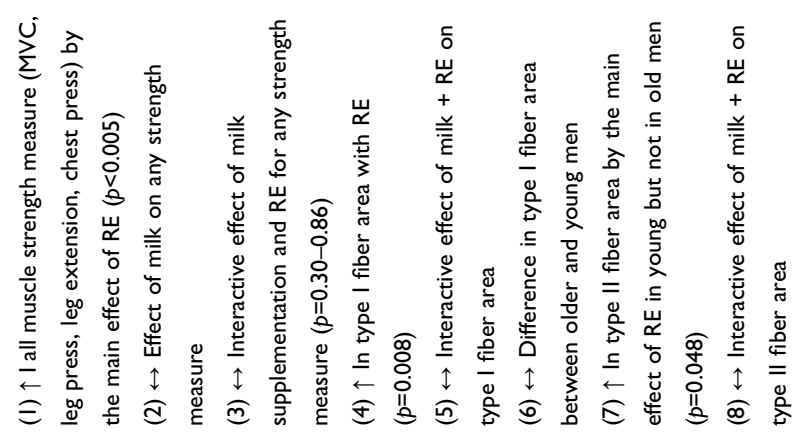 \\
\hline 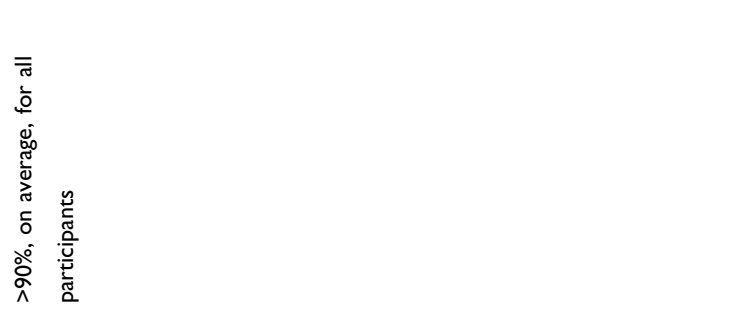 & 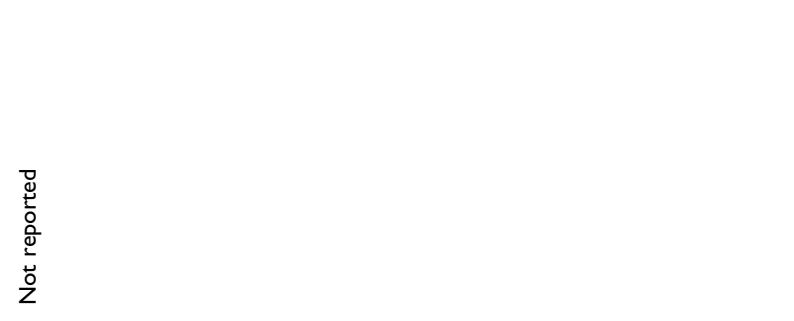 \\
\hline 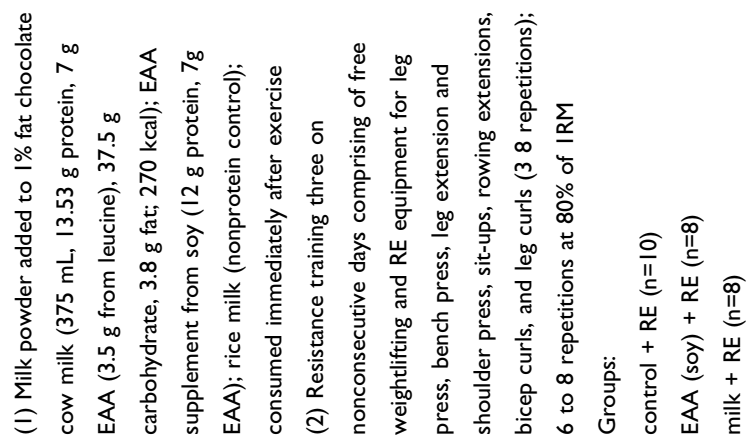 & 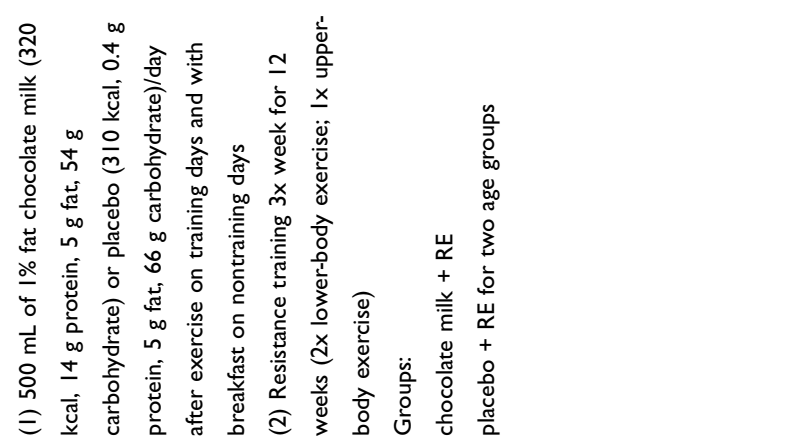 \\
\hline$\stackrel{\sim}{\sim}$ & 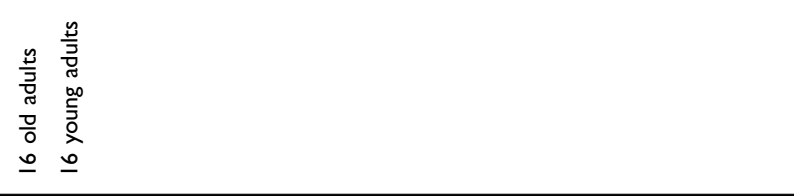 \\
\hline$\Sigma$ & $\Sigma$ \\
\hline & 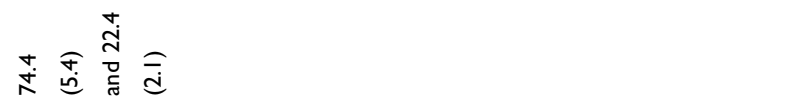 \\
\hline 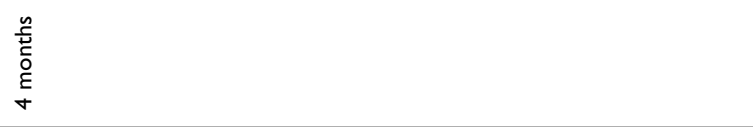 & 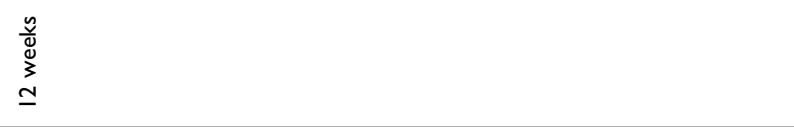 \\
\hline 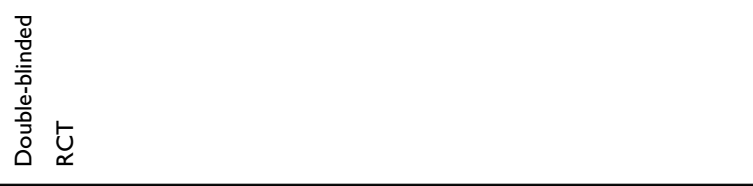 & $\underset{\substack{u\\
}}{u}$ \\
\hline $\begin{array}{l}\text { 褐 } \\
\text { Uू }\end{array}$ & 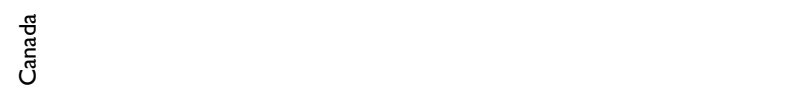 \\
\hline 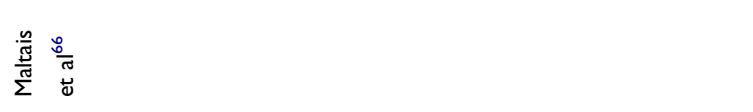 & 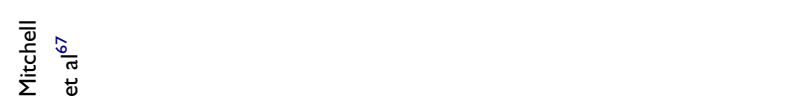 \\
\hline
\end{tabular}




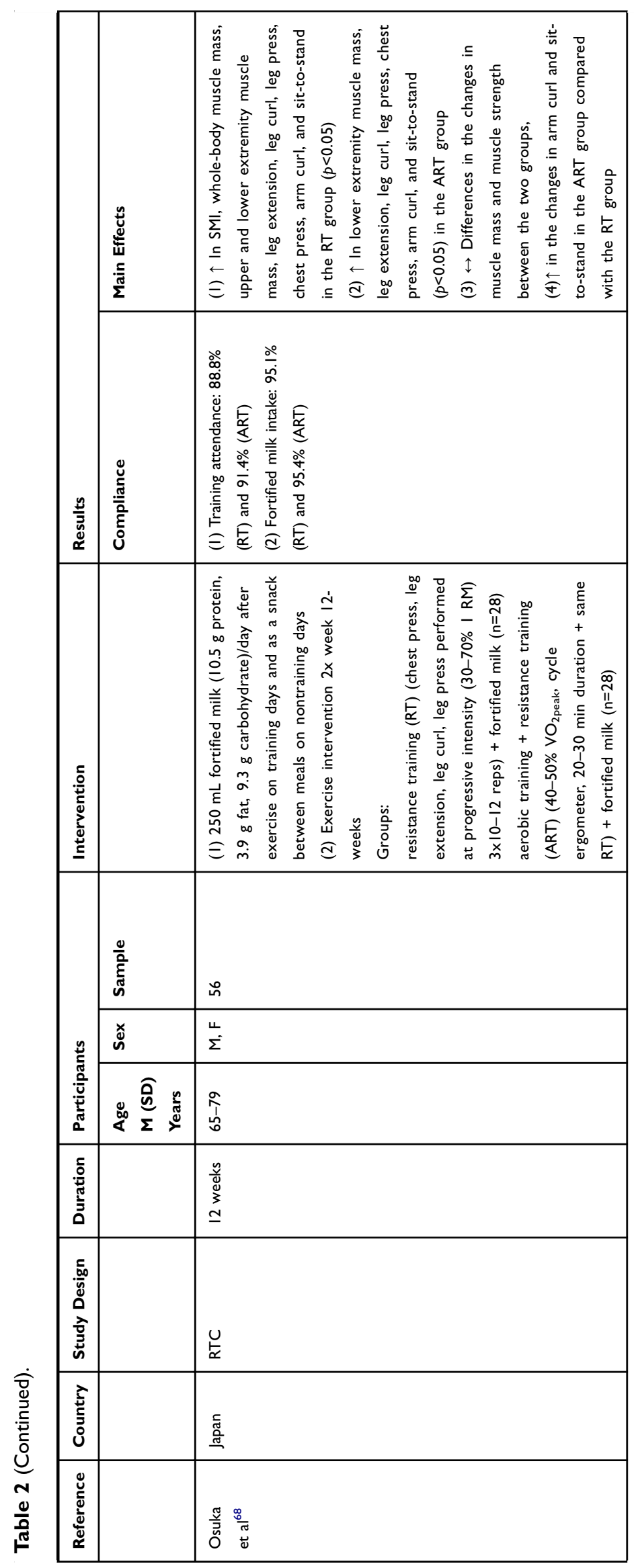




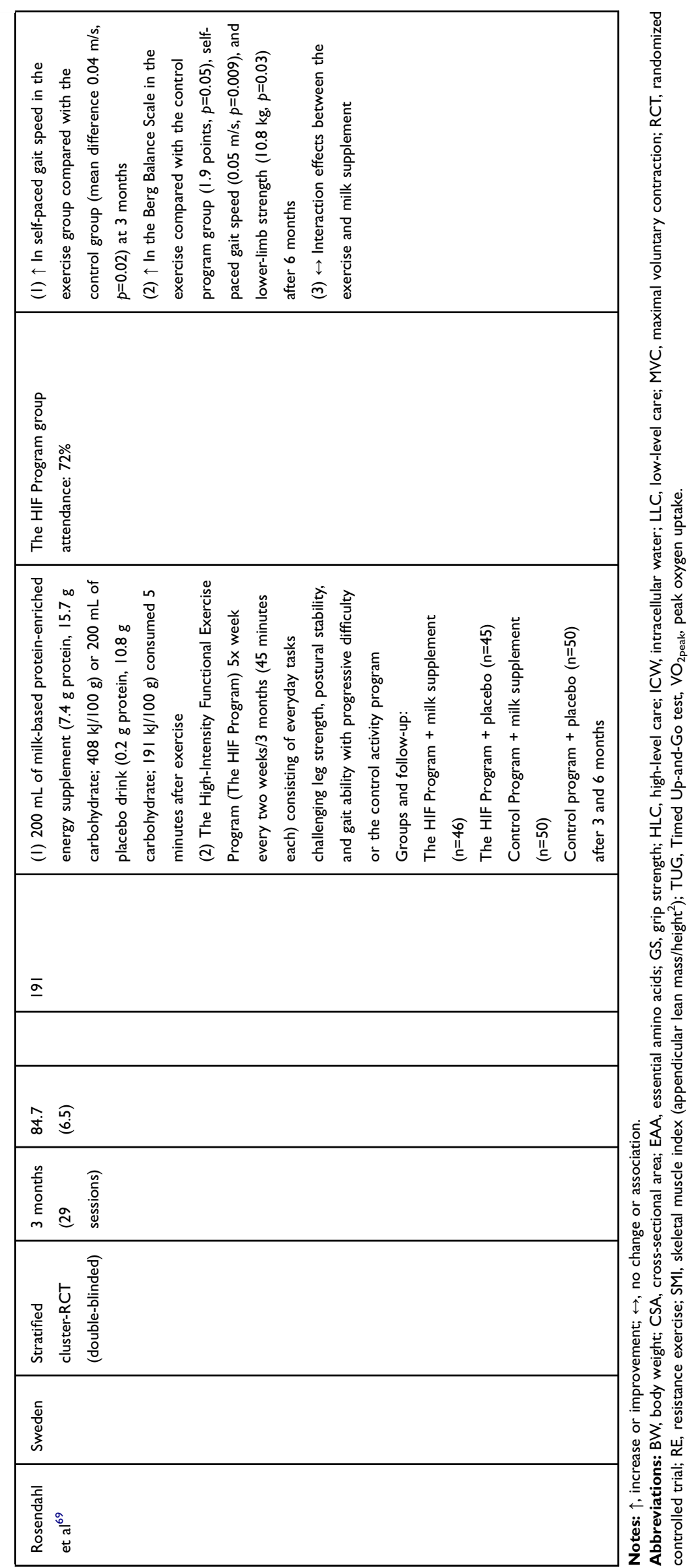


protein intake ( $>1.2 \mathrm{~g} / \mathrm{kg} \mathrm{BW} / \mathrm{d})$ at baseline. Whilst exercise significantly improved several muscle health outcomesstrength, lean mass (LM), muscle cross sectional area (CSA), and gait speed-compared with the no exercise group, no additional beneficial effects of milk beyond the effect of exercise were observed. Specifically, the gains in total body LM and mid-femur muscle CSA were two- to threefold greater in the exercise + fortified milk group compared with either group alone or the control group, but the interaction terms were not significant for any muscle or functional outcome after 18 months. The main effect analyses revealed that exercise significantly improved muscle strength $(\sim 20-52 \%, p<0.001)$, LM $(0.6 \mathrm{~kg}, p<0.05)$, muscle CSA $(1.8 \%, p<0.001)$, and gait speed $(11 \%, p<0.05)$ compared with the no exercise group. Moreover, the fortified milk had no effect on muscle size, strength, or function.

Similar findings were noted in a study involving older adults living in a residential care facility with poor nutritional status and limitations in activities of daily living. Improvements in balance, gait speed and lower-limb strength were driven by a three-month high-intensity functional exercise program with no additional benefits from combining exercise with a milk-based protein supplement. ${ }^{69}$ Specifically, there was a significant improvement in gait speed in the exercise compared with the control group (mean difference $0.04 \mathrm{~m} / \mathrm{s}, p=0.02$ ) at three months, and significant improvements in balance (Berg Balance Scale, 1.9 points, $p=0.05)$, gait speed $(0.05 \mathrm{~m} / \mathrm{s}, p=0.009)$, and lower-limb strength $(10.8 \mathrm{~kg}, p=0.03)$ after six months follow-up. However, no interaction effects were observed between the exercise and nutrition interventions (ie, milk-based proteinenriched energy supplement). This could be partially explained by the additional protein being oxidized to generate energy to compensate for a negative energy balance in malnourished older women. ${ }^{69}$ In another study involving residential care residents with severe physical and cognitive impairment, no change in intracellular water (ICW), a proxy for muscle mass, was observed following a three-month intervention involving an exercise program and milk-based protein enriched drink providing $\sim 15 \mathrm{~g}$ of protein after exercise.$^{64}$ For example, the between-group difference in ICW in exercise vs control activity group were not significant (mean 95\% CI: -0.2 ( -0.7 to 0.3$), p=0.37$ ), and no differences were observed between the protein drink vs placebo drink group $(-0.2$ ( -0.7 to 0.3$), p=0.53$ ). In both studies all participants were assessed to be at risk of malnutrition (the Mini Nutritional Assessment score $<24$ ), which may have explained negative findings for muscle anabolism. Osuka et $\mathrm{al}^{68}$ compared the effect of a combination of aerobic and resistance training (ART) followed by consumption of fortified milk (10.5 $\mathrm{g}$ of protein) against RT with fortified milk on muscle mass, strength and function in healthy community-dwelling older adults after 12 weeks of intervention. No between-group differences in muscle mass were reported, but SMI, whole-body muscle mass, upper-extremity muscle mass were increased in the RT with the fortified milk group, whereas lower-extremity muscle mass was increased in both groups. Muscle strength (leg extension strength, leg curl, leg press, chest press, arm curl) and the time to complete chair stands also improved in both groups, with the ART + fortified milk group improving significantly more compared with the $\mathrm{RT}+$ fortified milk group (9.0 \pm 5.5 vs $5.3 \pm 3.8, p=0.005$ arm curls per $30 \mathrm{~s}$, and 5.9 \pm 3.9 vs $3.2 \pm 4.1,=0.01$ chair rises per $30 \mathrm{~s}$ ). In both intervention groups protein intake was $>1.3 \mathrm{~g} / \mathrm{kg} \mathrm{BW} / \mathrm{d}$ at baseline. Lack of a comparator group limits the interpretation of the study findings, to address whether fortified milk provided any benefits on muscle health outcomes.

Two studies ${ }^{66,67}$ have evaluated the use of a chocolate milk-based drink, with Maltais et al ${ }^{66}$ comparing EAA supplement (12 $\mathrm{g}$ of protein, $7 \mathrm{~g}$ of EAA from soy) against milk supplement (13.5 $\mathrm{g}$ of protein, $7 \mathrm{~g}$ of EAA) and nonprotein control (rice milk) in older men with low muscle mass index (MMI, muscle mass/high). All groups completed a 4-month resistance training program three times a week. All participants improved significantly in several parameters of muscle mass (ie, lean body mass, MMI and total muscle mass) and muscle strength (lateral pull down 1-RM), but no betweengroup differences were observed. For example, all groups experienced significant change in MMI (control group: 0.52 (0.32) $\mathrm{kg} / \mathrm{m}^{2}$; EAA group: $0.95(0.55) \mathrm{kg} / \mathrm{m}^{2}$, and milk group: $0.65(0.47) \mathrm{kg} / \mathrm{m}^{2}, p$ for all $\left.\leq 0.05\right)$. For physical capacity, only the EAA group improved in the TUG test. The study had only $8-10$ participants per group and all had protein intake $>0.8 \mathrm{~g} / \mathrm{kg} \mathrm{BW} / \mathrm{d}$. The authors concluded that RE was an effective way of improving muscle mass and strength regardless of protein supplementation. Conversely, a study that compared the effect of $500 \mathrm{~mL}$ non-supplemented chocolate milk (14 $\mathrm{g}$ of protein/day) with RE to placebo drink ( $0.4 \mathrm{~g}$ of protein) with RE in healthy young and old men after 12 weeks of intervention, found that milk did not enhance effects on skeletal muscle strength or hypertrophy following resistance training. Although a strong training effect was observed for all muscle strength measures (eg, 1$\mathrm{RM}$ for leg press, leg extension, and chest press in $\mathrm{kg}$; $p<0.005$ ), there was no significant interactive effect of 
chocolate milk supplementation $(p>0.3) \cdot{ }^{67}$ Protein intake pre-intervention was not reported.

In summary, several intervention studies have investigated how milk as a vehicle for protein and other nutrients may enhance the beneficial effect of resistance training on muscle mass, strength and function in older adults with and without functional impairments. Collectively, current evidence does not indicate any additional beneficial effects of milk supplementation beyond the positive effects of RE alone.

\section{Discussion}

\section{Milk for Muscle Health: Summary of Evidence and Implications}

Milk is a complex food constituted of nutrients and biologically active components with anabolic, anti-oxidative, anti-inflammatory, and immunomodulatory properties, which as a part of a balanced diet may provide myoprotection for aging muscle. However, there is limited evidence and current epidemiological and experimental research does not provide support for additional benefits of (unfortified or fortified) milk for muscle health and physical performance in older adults. Evidence from one observational study suggests that higher childhood intake of whole milk may have a beneficial effect on physical performance and balance in later life. ${ }^{60}$ The associations between higher adult intake of milk and muscle health were inconclusive and based on only two studies, warranting further research. ${ }^{60,61}$ Positive results observed for childhood milk intake and muscle function in later life need to be repeated in other populations.

In intervention studies (Table 2), (fortified) milk, alone or in the combination with resistance training, provided no benefits for muscle health. Specifically, two interventions with fortified milk showed no evidence for an independent effect of milk consumption on muscle strength and physical performance either in care residents ${ }^{62}$ or communitydwelling older adults. ${ }^{63}$ Although very limited, the results suggest that milk supplementation providing extra energy and protein above habitual consumption may not be effective or sufficient to improve muscle function in older adults with either higher dietary protein intake (ie, $>0.8 \mathrm{~g}$ of protein $/ \mathrm{kg} \mathrm{BW} / \mathrm{d}$ in both studies) or functional limitations. Of six intervention studies that combined exercise with (fortified) milk supplementation, five found the main effect of exercise on several parameters of muscle mass and function, ${ }^{65-69}$ but no interaction effect of the exercise and nutrition intervention in ether healthy communitydwelling older adults or in those residing in care homes. One study in care residents with functional impairments found no exercise or interaction effect on muscle mass, ${ }^{64}$ which could be explained by malnutrition and negative protein energy for muscle anabolism, multimorbidity, and inadequate intervention duration for this population to observe significant change.

Promising evidence for an interaction effect of milk and exercise has been observed in several intervention studies with younger adults and athletes, both men and women. ${ }^{19,43-45}$ A positive effect of (unfortified) milk immediately after exercise has been reported for lean muscle mass, strength, MPS, and loss of fat mass compared with control (isocaloric) or soybased drink, ${ }^{19,43-45}$ which the authors have contributed to the following mechanisms. Compared to other protein sources, milk proteins (especially whey) have greater ability to promote anabolism postexercise, resulting in lean muscle gain. ${ }^{19,45,48,59}$ Decreases in fat mass have been explained by the interplay between parathyroid hormone, vitamin D metabolites, medium-chain fatty acids, bioactive peptides and serum calcium affecting cellular lipolysis (adipocytes lipid metabolism) and fatty acids absorption, thus resulting in loss of fat mass (discussed in Dougkas et al). ${ }^{70}$

However, the results from interventions studies combining fortified milk with exercise in older adults were inconclusive, and several limitations of the studies have been recognized by the authors. These include: (1) sample size and lack of power to detect change in muscle health outcomes affecting the validity of the study in the population of interest; ${ }^{63-67}$ (2) lack of control group for proper comparison; ${ }^{62,65}$ (3) insufficient study duration to observe an effect in the population under study; ${ }^{62-64}$ (4) low milk (protein) dose to induce muscle fiber hypertrophy in older adults experiencing anabolic resistance ${ }^{66,67,69}(5)$ attrition and low compliance with the intervention; ${ }^{63}(6)$ a small treatment effect, suggesting low clinical importance of (fortified) milk in the study population; ${ }^{63,69}$ (7) selection bias toward healthy older adults; ${ }^{65,68}(8)$ low generalizability to older adult population; ${ }^{65,68}$ (8) no blinding of participants and assessors to the intervention; ${ }^{68,69}$ (9) lack of mechanistic studies; ${ }^{62,63,68}$ and (10) the timing of the nutrition intervention missing the "window of anabolic opportunity" (ie, the timing of the protein feeding exceeding 24 hours). ${ }^{65}$

Regardless of the differences across the studies (ie, participants, sample size, intervention type, duration, intensity, and muscle health outcomes), the results confirmed the 
effectiveness of resistance training for better muscle aging in healthy and older adults with sarcopenia. ${ }^{71,72}$ Importantly, the lack of the interaction effect between exercise and nutrition (milk) in all studies calls for a careful consideration of several factors that may have contributed to the null findings when designing future studies using a whole food approach (milk). These factors include: (1) nutrient (protein) dose in milk; (2) timing of milk (protein) consumption; (3) habitual protein intake; (4) insufficient understanding of the role of other nutrients in milk for MPS; and (5) difficulties recruiting older adults at risk of sarcopenia, who would likely benefit the most from these interventions. ${ }^{73,74}$

\section{Milk for Muscle Health: Possible Reasons for Lack of Beneficial Effects in Studies with Older Adults}

Provision of sufficient protein (ie, dose) within milk represents a key consideration, particularly for older adults who may exhibit anabolic resistance compared with younger adults. $^{30}$ Previous work has suggested that $>20$ g of protein per meal may be necessary to stimulate MPS in older adults, ${ }^{11-13,22,48}$ yet all RCTs combining milk supplementation and exercise ${ }^{64-69}$ (Table 2) have provided amounts below $20 \mathrm{~g}$ of protein/day either after exercise or every day during the study period. The two studies with milk supplementation intervention without exercise ${ }^{62,63}$ provided $>33 \mathrm{~g}$ of protein/day, but the absence of RE, a potent stimulus of MPS, may explain the negative results. A recent meta-analysis has indicated that there is no evidence to suggest that protein or EAA supplementation without concomitant exercise interventions increases muscle mass or strength in predominantly healthy older adults. ${ }^{75}$ However, a meta-analysis with meta-regression of 49 studies in healthy adults has shown that the effect of protein supplementation in augmenting RE-induced change in fatfree mass was effective in young adults ( $<40$ years) and less effective with advancing age ( $>40$ years), but ineffective beyond total protein intake of $\sim 1.6 \mathrm{~g} / \mathrm{kg} \mathrm{BW} /$ day. $^{76}$ This suggests that the protein dosage and the total protein intake may be the possible reasons for the negative results in the studies.

One challenge in collating this evidence is that the frequency of milk dose varied between the studies; three RCTs have provided nutritional supplement daily ${ }^{65,67,68}$ and three on the training days only, ${ }^{63,66,69}$ which makes the comparison between the studies challenging. Adherence to (fortified) milk drinking was $>80 \%$ across the studies, suggesting that milk drinking was feasible for older adults. However, a greater amount of milk is needed to provide a dose $>20 \mathrm{~g}$ of protein, which needs to be assessed in this population. ${ }^{77}$

An important consideration for maximizing potential adaptation is the timing of protein consumption. For example, a study involving older men has shown that ingestion of protein supplement (10 g protein) immediately postexercise (within five minutes) stimulated greater skeletal muscle hypertrophy compared with the ingestion two hours posttraining. ${ }^{78}$ However, a study comparing the effect of protein supplementation pre- and post-RE between young $(\leq 40$ years) and older men ( $\geq 59$ years) has found no effect of supplementation on muscle mass and strength in older adults. ${ }^{79}$ This suggests that the dosages of protein may be more important than timing. The timing of the milk intake in the RCTs with exercise component described in this review varied from five minutes after exercise, ${ }^{64,69}$ immediately after exercise ${ }^{66-68}$ to non-specific, ${ }^{65}$ the latter study possibly missing the "MPS window" post-RE stimulus for beneficial effect.

A key issue is the role of other nutrients present in milk, especially fats, which are rarely considered; the compositional differences in milk across the studies for MPS stimulation postexercise in older adults is unknown. There is some evidence that fat content may be important, as in a study of healthy young volunteers, Elliott et $\mathrm{al}^{59}$ demonstrated that milk ingestion-stimulated net MPS following RE was more effective in the whole milk than in fat-free milk group - a difference that was explained by higher net amino acid uptake, hypothesized to be related to a higher fat content in whole milk. However, compositional difference in milk across the reviewed studies (eg, supplemented with protein, ${ }^{63,64,66,68,69}$ vitamin $\mathrm{D}$ and $\mathrm{Ca},{ }^{62,65} \mathrm{EAA},{ }^{66}$ chocolate; ${ }^{66,67}$ reduced or low fat $(\leq 1.6 \%)$ in seven out of eight studies) makes the synthesis of their findings difficult, and the implications for future trials of milk supplementation challenging.

Another important point to consider relates to participants' habitual dietary protein intake in these studies. In all the studies of older independent adults for whom there were baseline dietary data (Table 2), habitual protein intakes were above the recommended intakes $(0.8 \mathrm{~g} / \mathrm{kg}$ $\mathrm{BW} / \mathrm{d}$ ), reaching $1.2-1.3 \mathrm{~g} / \mathrm{kg} \mathrm{BW} / \mathrm{d}$ in two studies. ${ }^{65,68}$ Thus increased protein $/ \mathrm{milk}$ consumption provided through the intervention was in populations that already consumed adequate amounts of protein for muscle health, and therefore unlikely to have a substantial additional 
effect on muscle outcomes. For example, in a study of healthy older men and women with adequate habitual protein intake, protein supplementation of $15 \mathrm{~g} /$ day after a prolonged resistance-type exercise program did not augment beneficial effect of exercise on muscle mass, strength and function. ${ }^{80}$ Similarly, in a recent RCT, the Liverpool Hope University - Sarcopenia Aging Trial, supplementation with a leucine-enriched whey protein isolate $(1.5 \mathrm{~g} / \mathrm{kg}$ $\mathrm{BW} / \mathrm{d}$ ) after resistance and functional exercise program did not provide any additional benefit in healthy older adults who already consumed sufficient amounts of dietary protein at study enrollment. ${ }^{81}$ Interestingly, the authors suggest that future trials should use whole protein-containing foods instead of supplements because of low compliance $(43 \pm 14 \%)$ to dietary-protein supplementation in this trial, which may have contributed to the null results. ${ }^{81}$

A big challenge to date for RCTs is the recruitment of older adults with sarcopenia, who may respond differently to the milk supplementation after RE treatment compared with those with lesser degrees of muscle dysfunction. In the present review only two trials included pre-sarcopenic older adults ${ }^{63,66}$ further research should determine whether those with different levels of skeletal muscle dysfunction respond differently to interventions.

Another challenge to consider in milk-based interventions with older adults relates to a substantial variation in milk consumption across the world regions, ${ }^{33}$ explained in part by affordability and environmental concerns related to animalbased protein production and consumption, ${ }^{22,23}$ and the presence of lactose intolerance (LI) and malabsorption in the populations. ${ }^{82}$ Although much LI is genetically predetermined (ie, lactase nonpersistence, LNP), self-reported LI has been estimated at a greater prevalence then LNP in a number of studies, with links to female gender, advanced age, race, body size, dose of lactose, and genetic differences in LNP. ${ }^{83,84}$ Also, the malabsorption of nutrients and gastrointestinal symptoms should be considered when designing nutritional interventions with whole foods, including milk and dairy in older adults. Nutrient absorption in older adults can be compromised by nutrient-drug interaction, atrophic gastritis leading to hypochlorhydria and altered acid-pepsin digestion, resulting in impaired absorption of vitamins and minerals, such as folate, vitamin B12, calcium, iron and $\beta$-carotene (discussed in Granic et al). ${ }^{85}$ In a study of 400 Finnish adults (aged 18-64 years), only milk protein IgG, not IgA antibodies were associated with self-perceived gastrointestinal symptoms, which have been suspected to be caused by milk indigestion in over $40 \%$ of adults in primary care. ${ }^{86}$
In summary, synthesizing findings from existing intervention studies (Table 2) presents a challenge because of differences in study design (eg, sample size, study arms), participants (eg, baseline fitness, habitual protein intake, sarcopenia status, setting) and intervention characteristics (eg, exercise training program, protein supplementation protocol, adherence/compliance to intervention). Current evidence does not show benefit of milk supplementation of older adults for muscle health. However, inadequate dose of protein (via milk), high habitual protein intakes, fitness and sarcopenia status at baseline may be among the main reasons for the lack of demonstrated effects of milk.

\section{Milk for Muscle Health: Areas for Future Aging Research}

There is relatively little evidence about the role of milk in muscle health and functioning and sarcopenia in older adults from both observational and intervention studies. A whole food approach in testing the nutrition-muscle health hypothesis emphasizes nutrient-dense foods that are affordable, sustainable, easy to prepare, and palatable to older adults. Liquid milk may be such a food because it contains nutrients and other bioactive components that have multiple myoprotective properties, which may act against several pathogenic pathways implicated in sarcopenia, including inflammation and oxidative stress. However, there are several obstacles facing observational and intervention research of muscle aging in reaching a higher level of evidence about the role of whole foods (milk) in treatment and prevention of sarcopenia. These include: (1) the type and amount of milk (eg, low-fat vs whole; readily available vs fortified); (2) the type, frequency and intensity of exercise intervention (resistance training vs resistance and functional training); (3) the harmonization of the operational definition of sarcopenia ${ }^{1,3}$ and muscle-related outcomes; (4) determination of target population (eg, sarcopenic vs at-risk population living in the community and residential care); (5) the timing of follow-up or intervention (weeks vs months); and (6) life stages (eg, a life course approach; mid vs late adulthood). Adequately powered RCTs of well characterized older adults likely to benefit from the interventions using a whole food approach are needed to test their effectiveness for healthy muscle ageing. In addition, milk may not be an appropriate functional food for mitigating loss of muscle mass and function for all older adults. For example, although higher milk and dairy intake has been associated with other positive health outcomes, ${ }^{34-43,47}$ lactose intolerance should be considered 
when designing RCTs with older adults with multimorbidities (eg, diabetes, obesity) and milk allergies. ${ }^{82-84}$

\section{Conclusions}

Milk contains biologically active nutrients and components that have anabolic, anti-inflammatory, anti-oxidative, and immunomodulating properties, and thus may be myoprotective. However, there is currently relatively little evidence from both observational and intervention studies with older adults about the benefits of milk as a functional food for muscle health. A limited number of studies summarized in this review included older adults that were mostly healthy, well-functioning, and well-nourished (ie, good protein intake), and varied greatly in the type, amount and timing of milk intake, length of intervention, and sarcopenia status. Sufficiently powered intervention studies in well characterized groups of older adults most likely to benefit from interventions are needed to test the effectiveness of a whole food approach, including milk, for healthy muscle aging.

\section{Acknowledgments}

This work was supported by the National Institute for Health Research Newcastle Biomedical Research Centre based at Newcastle Hospitals Foundation Trust and Newcastle University, Newcastle upon Tyne, UK (AG, CH, LD, AAS).

\section{Disclosure}

The authors report no conflict of interest in this work.

\section{References}

1. Cruz-Jentoft AJ, Sayer AA. Sarcopenia. Lancet. 2019;393 (10191):2636-2646. doi:10.1016/S0140-6736(19)31138-9

2. Goodpaster BH, Park SW, Harris TB, et al. The loss of skeletal muscle strength, mass, and quality in older adults: the health, aging and body composition study. J Gerontol a Biol Sci Med Sci. 2006;61(1):10591064. doi:10.1093/gerona/61.10.1059

3. Cruz-Jentoft AJ, Bahat G, Bauer J, et al. Sarcopenia: revised European consensus on definition and diagnosis. Age Ageing. 2019;48(1):16-31. doi:10.1093/ageing/afy169

4. Zhang Y, Hao Q, Ge M, Dong B. Association of sarcopenia and fractures in community-dwelling older adults: a systematic review and meta-analysis of cohort studies. Osteoporos Int. 2018;29 (6):1253-1262. doi:10.1007/s00198-018-4429-5

5. Liu P, Hao Q, Hai S, Wang H, Cao L, Dong B. Sarcopenia as a predictor of all-cause mortality among community-dwelling older people: a systematic review and meta-analysis. Maturitas. 2017;103:16-22. doi:10.1016/j.maturitas.2017.04.007

6. Liccini A, Malmstrom TK. Frailty and sarcopenia as predictors of adverse health outcomes in persons with diabetes mellitus. $J$ Am Med Dir Assoc. 2016;17(9):846-851. doi:10.1016/j.jamda.2016.07.007

7. Zhang X, Zhang W, Wang C, Tao W, Dou Q, Yang Y. Sarcopenia as a predictor of hospitalization among older people: a systematic review and meta-analysis. BMC Geriatr. 2018;18(1):188. doi:10.1186/s12877018-0878-0
8. Liguori I, Russo G, Aran L, et al. Sarcopenia: assessment of disease burden and strategies to improve outcomes. Clin Interv Aging. 2018;13:913-927. doi:10.2147/CIA.S149232

9. Sayer AA, Robinson SM, Patel HP, Shavlakadze T, Cooper C, Grounds MD. New horizons in the pathogenesis, diagnosis and management of sarcopenia. Age Ageing. 2013;42(2):145-150. doi:10.1093/ageing/afs191

10. Dhillon RJ, Hasni S. Pathogenesis and management of sarcopenia. Clin Geriatr Med. 2017;33(1):17-26.

11. Calvani R, Miccheli A, Lando F, et al. Current nutritional recommendations and novel dietary strategies to manage sarcopenia. $J$ Frailty Aging. 2013;2(1):38-53.

12. Landi F, Calvani M, Tosato M, et al. Protein intake and muscle health in old age: from biological plausibility to clinical evidence. Nutrients. 2016;8(5):295. doi:10.3390/nu8050295

13. Bauer J, Biolo G, Cederholm T. Evidence-based recommendations for optimal dietary protein intake in older people: a position paper from the PROT-AGE Study Group. JAMDA. 2013;14(8):542-559. doi:10.1016/j.jamda.2013.05.021

14. Houston DK, Nicklas BJ, Ding J, et al. Dietary protein intake is associated with lean mass change in older, community-dwelling adults: the Health, Aging, and Body Composition (Health ABC) Study. Am J Clin Nutr. 2008;87(1):150-155. doi:10.1093/ajcn/87.1.150

15. Gregorio L, Brindisi J, Kleppinger A, et al. Adequate dietary protein is associated with better physical performance among post-menopausal women 60-90 years. J Nutr Health Aging. 2014;18(2):155-160. doi:10.1007/s12603-013-0391-2

16. Phillips SM, Martinson W. Nutrient-rich, high-quality, protein-containing dairy foods in combination with exercise in aging persons to mitigate sarcopenia. Nutr Rev. 2019;77(4):216-229. doi:10.1093/ nutrit/nuy062

17. Granic A, Sayer AA, Robinson SM. Dietary patterns, skeletal muscle health, and sarcopenia in older adults. Nutrients. 2019;11(4):745. doi: $10.3390 /$ nu 11040745

18. Kimball SR, Jefferson LS. Signaling pathways and molecular mechanisms through which branched-chain amino acids mediate translational control of protein synthesis. $J$ Nutr. 2006;136(1Supp 1):S227-S231. doi:10.1093/jn/136.1.227S

19. West DWD, Abou Sawan S, Mazzulla M, Williamson E, Moore DR. Whey protein supplementation enhances whole body protein metabolism and performance recovery after resistance exercise: a double-blind crossover study. Nutrients. 2017;9(7):735. doi:10.3390/nu9070735

20. Lancha AH Jr Zanella R Jr Tanabe SG, Andriamihaja M, Blachier F. Dietary protein supplementation in the elderly for limiting muscle mass loss. Amino Acids. 2017;49(1):33-47. doi:10.1007/s00726-016-2355-4

21. Hanach NI, McCullough F, Avery A. The impact of dairy protein intake on muscle mass, muscle strength, and physical performance in middle-aged to older adults with or without existing sarcopenia: a systematic review and meta-analysis. Adv Nutr. 2019;10(1):59-69. doi:10.1093/advances/nmy065

22. Lonnie M, Hooker E, Brunstrom JM, et al. Protein for life: review of optimal protein intake, sustainable dietary sources and the effect on appetite in ageing adults. Nutrients. 2018;10(3):360. doi:10.3390/nu10030360

23. Gardner CD, Hartle JC, Garrett RD, Offringa LC, Wasserman AS. Maximizing the intersection of human health and the health of the environment with regard to the amount and type of protein produced and consumed in the United States. Nutr Rev. 2019;77(4):197-215. doi:10.1093/nutrit/nuy073

24. Radavelli-Bagatini S, Zhu K, Lewis JR, Dhaliwal SS, Prince RL. Association of dairy intake with body composition and physical function in older community-dwelling women. J Acad Nutr Diet. 2013;113(12):1669-1674. doi:10.1016/j.jand.2013.05.019

25. Bauer JM, Verlaan S, Bautmans I, et al. Effects of a vitamin D and leucine-enriched whey protein nutritional supplement on measures of sarcopenia in older adults, the PROVIDE study: a randomized, double-blind, placebo-controlled trial. J Am Med Dir Assoc. 2015;16 (9):740-747. doi:10.1016/j.jamda.2015.05.021 
26. Pereira PC. Milk nutritional composition and its role in human health Nutrition. 2014;30(6):619-627. doi:10.1016/j.nut.2013.10.011

27. Haug A, Høstmark AT, Harstad OM. Bovine milk in human nutrition a review. Lipids Health Dis. 2007;6:25. doi:10.1186/1476-511X-6-25

28. Mills S, Ross RP, Hill C, Fitzgerald GF, Stanton C. Milk intelligence: mining milk for bioactive substances associated with human health. Int Dairy J. 2011;21(6):377-401. doi:10.1016/j.idairyj.2010.12.011

29. IOM. Dietary Reference Intakes; 2012.

30. Layman DK, Lönnerdal B, Fernstrom JD. Applications for $\alpha$-lactalbumin in human nutrition. Nutr Rev. 2018;76(6):444-460. doi:10. 1093/nutrit/nuy004

31. Jäkälä P, Vapaatalo H. Antihypertensive peptides from milk proteins. Pharmaceuticals (Basel). 2010;3(1):251-272. doi:10.3390/ph3010251

32. Butler G. Manipulating dietary PUFA in animal feed: implications for human health. Proc Nutr Soc. 2014;73(1):87-95. doi:10.1017/ S0029665113003790

33. Singh GM, Micha R, Khatibzadeh S, et al. Global, regional and national consumption of sugar-sweetened beverages, fruit juices, and milk: a systematic assessment of beverage intake in 187 countries. PLoS One. 2015;1098:e124845.

34. Huth PJ, DiRienzo DB, Miller GD. Major scientific advances with dairy foods in nutrition and health. J Diary Sci. 2006;89(4):12071221. doi:10.3168/jds.S0022-0302(06)72190-7

35. Feskanich D, Meyer HE, Fung TT, Bischoff-Ferrari HA, Willett WC. Milk and other dairy foods and risk of hip fracture in men and women. Osteoporos Int. 2018;29(2):385-396. doi:10.1007/s00198017-4285-8

36. Fardellone P, Séjourné A, Blain H, Cortet B, Thomas T. GRIO Scientific Committee. Osteoporosis: is milk a kindness or a curse? Joint Bone Spine. 2017;84(3):275-281. doi:10.1016/j.jbspin.2016.06.006

37. Huncharek M, Muscat J, Kupelnick B. Impact of dairy products and dietary calcium on bone-mineral content in children: results of a metaanalysis. Bone. 2008;43(2):312-321. doi:10.1016/j.bone.2008.02.022

38. Drouin-Chartier JP, Brassard D, Tessier-Grenier M, et al. Systematic review of the association between dairy product consumption and risk of cardiovascular-related clinical outcomes. Adv Nutr. 2016;7 (6):1026-1040. doi:10.3945/an.115.011403

39. Schwingshackl L, Hoffmann G, Schwedhelm C, et al. Consumption of dairy products in relation to changes in anthropometric variables in adult populations: a systematic review and meta-analysis of cohort studies. PLoS One. 2016;11(6):e0157461. doi:10.1371/journal.pone. 0157461

40. Crichton GE, Alkerwi A. Whole-fat dairy food intake is inversely associated with obesity prevalence: findings from the Observation of Cardiovascular Risk Factors in Luxembourg study. Nutr Res. 2014;34 (11):936-943. doi:10.1016/j.nutres.2014.07.014

41. Ralston RA, Truby H, Palermo CE, Walker KZ. Colorectal cancer and nonfermented milk, solid cheese, and fermented milk consumption: a systematic review and meta-analysis of prospective studies. Crit Rev Food Sci Nutr. 2014;54(9):1167-1179. doi:10.1080/10408398.2011.629 353

42. Moschonis G, van den Heuvel EG, Mavrogianni C, Singh-Povel CM, Leotsinidis M, Manios Y. Associations of milk consumption and vitamin $\mathrm{B}_{2}$ and $\mathrm{B} 12$ derived from milk with fitness, anthropometric and biochemical indices in children. The healthy growth study. Nutrients. 2016;8(10):634. doi:10.3390/nu8100634

43. Josse AR, Tang JE, Tarnopolsky MA, Phillips SM. Body composition and strength changes in women with milk and resistance exercise. Med Sci Sports Exerc. 2010;42(6):1122-1130. doi:10.1249/MSS.0b013e3181c8 $54 \mathrm{f} 6$

44. Hartman JW, Tang JE, Wilkinson SB, et al. Consumption of fat-free fluid milk after resistance exercise promotes greater lean mass accretion than does consumption of soy or carbohydrate in young, novice, male weightlifters. Am J Clin Nutr. 2007;86(2):373-381. doi:10. 1093/ajcn/86.2.373
45. Wilkinson SB, Tarnopolsky MA, MacDonald MJ, Macdonald JR, Armstrong D, Phillips SM. Consumption of fluid skim milk promotes greater muscle protein accretion after resistance exercise than does consumption of an isonitrogenous and isoenergetic soy-protein beverage. $\mathrm{Am}$ J Clin Nutr. 2007;85(4):1031-1040. doi:10.1093/ajcn/85.4.1031

46. Vliet SV, Beals JW, Martinez IG, Skinner SK, Burd NA. Achieving optimal post-exercise muscle protein remodeling in physically active adults through whole food consumption. Nutrients. 2018;10(2):224. doi:10.3390/nu10020224

47. James LJ, Stevenson EJ, Rumbold PLS, Hulston CJ. Cow's milk as a post-exercise recovery drink: implications for performance and health. Eur J Sport Sci. 2019;19(1):40-48. doi:10.1080/17461391. 2018.1534989

48. Devries MC, Phillips SM. Supplemental protein in support of muscle mass and health: advantage whey. J Food Sci. 2015;80(Suppl 1):A8A15. doi:10.1111/1750-3841.12802

49. Dickinson JM, Fry CS, Drummond MJ, et al. Mammalian target of rapamycin complex 1 activation is required for the stimulation of human skeletal muscle protein synthesis by essential amino acids. $J$ Nutr. 2011;14(5):856-862. doi:10.3945/jn.111.139485

50. Moore DR, Churchward-Venne TA, Witard O, et al. Protein ingestion to stimulate myofibrillar protein synthesis requires greater relative protein intakes in healthy older versus younger men. $J$ Gerontol a Biol Sci Med Sci. 2015;70(1):57-62. doi:10.1093/gerona/glu103

51. Cermak NM, Res PT, de Groot LC, Saris WH, van Loon LJ. Protein supplementation augments the adaptive response of skeletal muscle to resistance-type exercise training: a meta-analysis. Am J Clin Nutr. 2012;96(6):1454-1464. doi:10.3945/ajcn.112.037556

52. Meng SJ, Yu LJ. Oxidative stress, molecular inflammation and sarcopenia. Int J Mol Sci. 2010;11(4):1509-1526. doi:10.3390/ijms11041509

53. Guerin J, Burgain J, Gomand F, Scher J, Gaiani C. Milk fat globule membrane glycoproteins: valuable ingredients for lactic acid bacteria encapsulation? Crit Rev Food Sci Nutr. 2019;59(4):639-651. doi:10.1080/10408398.2017.1386158

54. Beyer I, Mets T, Bautmans I. Chronic low-grade inflammation and age-related sarcopenia. Curr Opin Clin Nutr Metab Care. 2012;15 (1):12-22. doi:10.1097/MCO.0b013e32834dd297

55. Dupont J, Dedeyne L, Dalle S, Koppo K, Gielen E. The role of omega-3 in the prevention and treatment of sarcopenia. Aging Clin Exp Res. 2019;31(6):825-836. doi:10.1007/s40520-019-01146-1

56. Wilson D, Jackson T, Sapey E, Lord JM. Frailty and sarcopenia: the potential role of an aged immune system. Ageing Res Rev. 2017;36:1-10. doi:10.1016/j.arr.2017.01.006

57. Band MM, Sumukadas D, Struthers AD, et al. Leucine and ACE inhibitors as therapies for sarcopenia (LACE trial): study protocol for a randomised controlled trial. Trials. 2018;19(1):6. doi:10.1186/ s13063-017-2390-9

58. Sumukadas D, Witham MD, Struthers AD, McMurdo ME. ACE inhibitors as a therapy for sarcopenia - evidence and possible mechanisms. $J$ Nutr Health Aging. 2008;12(7):480-485. doi:10.10 07/BF02982709

59. Elliot TA, Cree MG, Sanford AP, et al. Milk ingestion stimulates net muscle protein synthesis following resistance exercise. Med Sci Sports Exerc. 2006;38(4):667-674. doi:10.1249/01.mss.0000210 190.64458 .25

60. Birnie K, Martin RM, Gallacher J, et al. Socio-economic disadvantage from childhood to adulthood and locomotor function in old age: a lifecourse analysis of the Boyd Orr and Caerphilly prospective studies. J Epidemiol Community Health. 2011;65(11):1014-1023. doi:10.1136/jech.2009.103648

61. Perala M, von Bonsdorff M, Mannisto S, Salonen MK. A healthy Nordic diet and physical performance in old age: findings from the longitudinal Helsinki Birth Cohort Study. Br J Nutr. 2016;115 (5):878-886. doi:10.1017/S0007114515005309 
62. Grieger JA, Nowson CA. Use of calcium, folate, and vitamin D3fortified milk for 6 months improves nutritional status but not bone mass or turnover, in a group of Australian aged care residents. J Nutr Elder. 2009;28(3):236-254. doi:10.1080/01639360903140130

63. Ottestad I, Løvstad AT, Gjevestad GO, et al. Intake of a proteinenriched milk and effects on muscle mass and strength. A 12-week randomized placebo controlled trial among community-dwelling older adults. J Nutr Health Aging. 2017;21(10):1160-1169. doi:10.1007/s12603-016-0856-1

64. Carlsson M, Littbrand H, Gustafson Y, et al. Effects of high-intensity exercise and protein supplement on muscle mass in ADL dependent older people with and without malnutrition-A randomized controlled trial. J Nutr Health Aging. 2011;15(7):554-560. doi:10.1007/ s12603-011-0017-5

65. Kukuljan S, Nowson CA, Sanders K, Daly RM. Effects of resistance exercise and fortified milk on skeletal muscle mass, muscle size, and functional performance in middle-aged and older men: an 18-mo randomized controlled trial. J Appl Physiol. 2009;107(6):18641873. doi:10.1152/japplphysiol.00392.2009

66. Maltais ML, Ladouceur JP, Dionne IJ. The effect of resistance training and different sources of postexercise protein supplementation on muscle mass and physical capacity in sarcopenic elderly men. $J$ Strength Cond Res. 2016;30(6):1680-1687. doi:10.1519/JSC.000 0000000001255

67. Mitchell CJ, Oikawa SY, Ogborn DI, et al. Daily chocolate milk consumption does not enhance the effect of resistance training in young and old men: a randomized controlled trial. Appl Physiol Nutr Metab. 2014;40(2):199-202. doi:10.1139/apnm-2014-0329

68. Osuka Y, Fujita S, Kitano N, et al. Effects of aerobic and resistance training combined with fortified milk on muscle mass, muscle strength, and physical performance in older adults: a randomized controlled trial. J Nutr Health Aging. 2017;21(10):1349-1357. doi:10.1007/s12603-016-0864-1

69. Rosendahl E, Lindelöf N, Littbrand H, et al. High-intensity functional exercise program and protein enriched energy supplement for older persons dependent in activities of daily living: a randomised controlled trial. Aust J Physiother. 2006;52(2):105-113. doi:10.1016/ S0004-9514(06)70045-9

70. Dougkas A, Reynolds CK, Givens ID, Elwood PC, Minihane AM. Associations between dairy consumption and body weight: a review of the evidence and underlying mechanisms. Nutr Res Rev. 2011;24 (1):72-95. doi:10.1017/S095442241000034X

71. Peterson MD, Rhea MR, Sen A, Gordon PM. Resistance exercise for muscular strength in older adults: a meta-analysis. Ageing Res Rev. 2010;9(3):226-237. doi:10.1016/j.arr.2010.03.004

72. Papa EV, Dong X, Hassan M. Resistance training for activity limitations in older adults with skeletal muscle function deficits: a systematic review. Clin Interv Aging. 2017;12:955-961. doi:10.2147/CIA. S104674
73. Witham MD, George J. Clinical trial design for older people-time for a rethink. QJM. 2014;107(1):15-16. doi:10.1093/qjmed/hct178

74. Witham MD, Stott DJ. A new dawn for sarcopenia. Age Ageing. 2019;48(1):2-3. doi:10.1093/ageing/afy171

75. Tieland M, Franssen R, Dullemeijer C, et al. The impact of dietary protein or amino acid supplementation on muscle mass and strength in elderly people: individual participant data and meta-analysis of RCT's. J Nutr Health Aging. 2017;21(9):994-1001. doi:10.1007/ s12603-017-0896-1

76. Morton RW, Murphy KT, McKellar SR, et al. A systematic review, meta-analysis and meta-regression of the effect of protein supplementation on resistance training-induced gains in muscle mass and strength in healthy adults. Br J Sports Med. 2018;52(6):376-384. doi:10.1136/bjsports-2017-097608

77. Granic A, Hurst C, Dismore L, et al. Milk and resistance exercise intervention to improve muscle function in community-dwelling older adults at risk of sarcopenia (MIlkMAN): protocol for a pilot study. BMJ Open. 2019;9(10):e031048. doi:10.1136/bmjopen-2019031048

78. Esmarck B, Andersen JL, Olsen S, Richter EA, Mizuno M, Kjaer M. Timing of postexercise protein intake is important for muscle hypertrophy with resistance training in elderly humans. $J$ Physiol. 2001;535(Pt 1):301-311. doi:10.1111/j.1469-7793.2001.00301.x

79. Candow DG, Chilibeck PD, Facci M, Abeysekara S, Zello GA. Protein supplementation before and after resistance training in older men. Eur J Appl Physiol. 2006;97(5):548-556. doi:10.1007/s00421006-0223-8

80. Leenders M, Verdijk LB, Van der Hoeven L, et al. Protein supplementation during resistance-type exercise training in the elderly. Med Sci Sports Exerc. 2013;45(3):542-552. doi:10.1249/MSS.0b013e318272fcdb

81. Kirk B, Mooney K, Amirabdollahian F, Khaiyat O. Exercise and dietary-protein as a countermeasure to skeletal muscle weakness: liverpool Hope University - Sarcopenia Aging Trial (LHU-SAT). Front Physiol. 2019;10:445. doi:10.3389/fphys.2019.00445

82. Fassio F, Facioni MS, Guagnini F. Lactose maldigestion, malabsorption, and intolerance: a comprehensive review with a focus on current management and future perspectives. Nutrients. 2018;10(11):1599. doi:10.3390/nu10111599

83. Suchy FJ, Brannon PM, Carpenter TO, et al. NIH consensus development conference statement: lactose intolerance and health. NIH Consens State Sci Statements. 2010;27(2):1-27.

84. Lapides RA, Savaiano DA. Gender, age, race and lactose intolerance: is there evidence to support a differential symptom response? A scoping review. Nutrients. 2018;10(12):1956. doi:10.3390/nu10121956

85. Granic A, Mendonça N, Hill TR, et al. Nutrition in the very old. Nutrients. 2018;10(3):269. doi:10.3390/nu10030269

86. Anthoni S, Savilahti E, Rautelin H, Kolho K-L. Milk protein IgG and IgA: the association with milk-induced gastrointestinal symptoms in adults. World J Gastroenterol. 2009;15(39):4915-4918. doi:10.3748/ wjg. 15.4915
Clinical Interventions in Aging

\section{Publish your work in this journal}

Clinical Interventions in Aging is an international, peer-reviewed journal focusing on evidence-based reports on the value or lack thereof of treatments intended to prevent or delay the onset of maladaptive correlates of aging in human beings. This journal is indexed on PubMed Central, MedLine, CAS, Scopus and the Elsevier
Bibliographic databases. The manuscript management system is completely online and includes a very quick and fair peer-review system, which is all easy to use. Visit http://www.dovepress.com/ testimonials.php to read real quotes from published authors. 